\title{
Fire Control and Suppression by Water-Mist Systems
}

\author{
Paolo E. Santangelo* and Paolo Tartarini
}

Dipartimento di Ingegneria Meccanica e Civile (DIMeC), Università degli Studi di Modena e Reggio Emilia, Via Vignolese 905/b, 41125 Modena, Italy

\begin{abstract}
The present work is an attempt to offer a comprehensive review of literature contributions, phenomenology and relevant results on water-mist systems. In particular, the water mist characterization and behavior in the field of fire control and suppression have been identified as the main areas of investigation. Some key parameters have been analyzed to gain a quantitative evaluation of the physical phenomena related to water-mist systems.

The water-mist fire suppression systems are an excellent alternative to halon fire protection systems, and they are now being used in many areas, including marine and industrial applications. Therefore, a wide survey of the complete number of literature works on this topic would exceed the full length of the present paper and only some examples of important contributions will be mentioned here. This paper proposes an introductory list of relevant literature works and this reference survey is then deepened with work and result details on suppression mechanisms, spray characterizations and experimental and numerical approaches. The final summary stresses out that a lot of experimental and numerical research and much application experience are still needed to gain better knowledge on water-mist systems, even if they already seem to be very promising in terms of efficiency and potentialities in fire control and suppression.
\end{abstract}

Keywords: Water mist, sprays, droplets, fire suppression, heat transfer.

\section{INTRODUCTION AND BACKGROUND}

Sprays are largely employed in many areas. As an example, thermal control and cooling are now mainly performed through spray application. Water appears to be the most appealing fluid to serve this purpose: cooling of mechanical components, like gas-turbine blades or pistons, is usually realized by sprayed water droplets. Moreover, additives are now commonly introduced to enhance particular properties of the spray, such as adhesion or jet penetration. The broad field underlying the present paper is fire protection. It represents a main setting for fundamental and applied studies and also a subject of interest for engineering applications. Many aspects are involved: among them, physics related to transport phenomena is certainly one of the most challenging.

Sprays have been employed in this field for many years and water has been the most employed fluid, but not the unique. Traditional sprinklers have been widely studied and investigated: a large body of analyses is available to both design them and predict their behavior. On the other hand, innovative technologies are now increasing their popularity, being water mist one of the most appealing. Research on them is strongly in demand from various points of view, as far as practical applications should be supported by basic comprehension of the involved physical phenomena. Therefore, spray characterization and flow-flame interaction represents one of the main subjects in this frame, the same way it does for fire protection in general. Moreover, some knowledge transfer can be successfully carried out from the

*Address correspondence to this author at the Dipartimento di Ingegneria Meccanica e Civile (DIMeC), Università degli Studi di Modena e Reggio Emilia, Via Vignolese 905/b, 41125 Modena, Italy; Tel.: +39 059205 6313; Fax: +39059 205 6126; E-mail: paoloemilio.santangelo@unimore.it propulsion to the fire-fighting field. Especially from experimental and numerical point of view, the same techniques and approaches can be applied to both fields with no change in value. However, even if investigation parameters are the same, working conditions (operative fluid, surroundings, etc.) and scale of the problem are largely different.

Water-mist systems appeared in the market in the ' $50 \mathrm{~s}$ because highly atomized water was discovered to be particularly efficient in heat absorption. As a matter of fact, water mist plays its role most in fire control and quenching, even if it also realizes a strong direct action in fire suppression. In spite of the good effectiveness of this technology, its appeal was initially low. High values of injection pressure to gain a proper jet fragmentation represented a strong economic disadvantage compared to traditional sprinklers and the tiny size of orifices was an excessive challenge for large-scale production and maintenance. However, the main competitors to water-mist systems were halogenated hydrocarbons (the halons, e.g.: halon 1301, the most popular). Their success was due to their capability of fire suppressing with neither damage nor residual in the fire scenario: this feature made them become widely employed everywhere sensitive items were placed (computer rooms, hospitals, etc.). In 1987 the Montreal Protocol ratified the target of bringing down all the substances which could reduce the ozone layer in stratosphere. It was a key point: halons' use dramatically flopped down and water-mist systems restarted to gain popularity. Water-based systems had to be improved and water mist appeared to be a promising solution for applications where gases could not be used.

Another important feature of water-mist systems is the low quantity of stored water they need with respect to traditional sprinkler-based ones. This issue set the former's suc- 
cess over the latter in mobile applications (naval and aerospace): the strong need for space and weight-saving systems represented a practical reason for industry to choose water mist, even if more expensive. Especially the naval field seems to be strongly water-mist oriented. Once the IMO (International Maritime Organization) ordered to provide direct fire-protection systems in any ship carrying more than 35 passengers, water-mist technology seemed to be the best one in complying both legal rules and design constraints. In addition, water mist seems to be more suitable than traditional sprinklers also for some stationary applications. Water mist can be employed in every setting where an excessive water sprinkling has to be avoided (museums, archives, areas with electric wires or cables, etc.), because of the extreme jet atomization and thereby the rapid droplet evaporation.

Nowadays, the most pressing engineering problem related to water-mist technology is regulation on the design of these systems. Many countries do not have any specific standard or legal reference as a guidance to quantitatively define the layout of these systems. The first and most obeyed document is the American NFPA 750 [1]. It consists of a set of directions to design, install, test and perform maintenance on a water-mist setup. It is worthwhile to introduce the definitions of fire control, suppression and extinguishment, which are clearly expressed in the NFPA 750 standard. Fire control is "the limitation of the growth of a fire by prewetting adjacent combustibles and controlling ceiling gas temperatures to prevent structural damage"; fire suppression is "the sharp reduction of the rate of heat release of a fire and the prevention of regrowth"; finally, fire extinguishment may be achieved as a sort of full suppression and is defined as "the complete suppression of a fire until there are no burning combustibles". Water-mist systems appear to be capable of successfully performing fire control and suppression in a large variety of fire scenarios, while extinguishment is reached only under certain configurations of both the fire case and the system parameters. A large body of studies on these aspects of fire protection by water mist is overviewed in the present work as the main objective.

Other important characteristics of NFPA 750 standard are to clearly define all the components and to categorize different system typologies in respect to different case scenarios; even though several indications are provided, no specific performance criterion is reported and a strong role is entrusted to probate authorities, who are entitled to judge the suitability of a particular water-mist installation to the case it is applied to. This standard emphasizes the strong need for experimental research on these systems: in particular, realscale tests are recommended to thoroughly understand control and quenching effectiveness. From the European side, a first draft has been realized in the frame of standard CENTC191-WG5. It appears to follow the American NFPA 750 adding some guidance for a generic system to obtain the CE approval. Some important design parameters, the nozzle distribution and the water-flow rate per surface unit, are still addressed and not quantitatively discussed. However, the latter parameter is still questioned because it is not clear whether the system should be designed on surface or volume-unit basis. Another primary reference is the standard FM5560 [2], released by FM Global. It is similar to the NFPA 750, but it shows more strict performance requirements. Moreover, it is subdivided in two parts: the first one reports a detailed classification of the components and the second one describes a thorough series of tests aimed at challenging the system in respect to a number of potential fire scenarios. Therefore, the importance of experimental activities in this field seems to be strongly recommended by both academia and industrial world. In particular, the FM5560 tests constitute a major reference for scientific research, defining a variety of scenarios and a procedure to measure a prescribed number of parameters. Thus, the experimental results can usefully be employed to validate theoretical and numerical models, which are now sought and studied to predict the behavior of water-mist technology.

It would be worthwhile to express a proper definition of water mist before going through the study of the spray jet. Unfortunately, a precise definition can hardly be found. Anyway, two parameters are used to make a quantitative distinction between traditional-sprinkler and water-mist sprays: drop size and operative pressure. The former can be expressed in several ways. A spray is constituted by a number of droplets, which can be approximately seen as spheres: the spray presents a distribution of different values of diameter, each one referred to a share of the total amount of droplets. Therefore, a definition of an overall parameter has been in demand by academia and industry since the beginning of spray studies. With regard to the water-mist field, characteristic drop size is usually expressed as $D_{\mathrm{v} f}$ : it is the representative diameter $D$, where a fraction $f$ of the total sprayed volume consists of droplets having diameters smaller than the stated value. This way allows a very straight technical approach to gain a quantitative value, because most experimental devices measure the cumulative distribution. Therefore, a volumetric-fraction-based diameter can be easily detected. The most common characteristic drop sizes are the $D_{v 50}$ (fraction equal to $50 \%$ ), which has also been largely used in the frame of this research, and $\mathrm{D}_{\mathrm{v} 90}$ (fraction equal to $90 \%$ ). The already mentioned NFPA 750 refers to $D_{v 90}$ to define water-mist sprays: it has to be lower than $1000 \mu \mathrm{m}$. A deeper categorization is also provided based on this parameter.

Water-mist systems are subdivided over 3 classes: class I refers to range $100-200 \mu \mathrm{m}$, class II to range $200-400 \mu \mathrm{m}$ and class III to range $400-1000 \mu \mathrm{m}$. The mentioned classification can be represented in diagrams like the one reported in Fig. (1): it summarizes and gathers the typical outputs of experimental instruments used to measure drop size. The basic scope of these devices is to yield the drop-size distribution as a function of both mass and volumetric fraction.

As mentioned before, operative pressure is also a parameter used to define a water-mist system. The NFPA 750 reports a pressure-based classification: low-pressure systems work below 12.5 bar, medium-pressure work in the range 12.5-35 bar, while high-pressure work above 35 bar. This last value is just an established convention: from a technical point of view, working pressure in water-mist systems is usually higher than 50 bar and goes up to 100 bar. As a matter of fact, the primary difference between water-mist technology and traditional sprinklers is glaring: the need for smaller droplets (the proper mist) brings to definitely higher values of pressure (operative pressure in traditional sprinklers stays in the range 2-5 bar). Therefore, different nozzles (atomizers) are employed with respect to this governing parameter (Fig. (2)). 


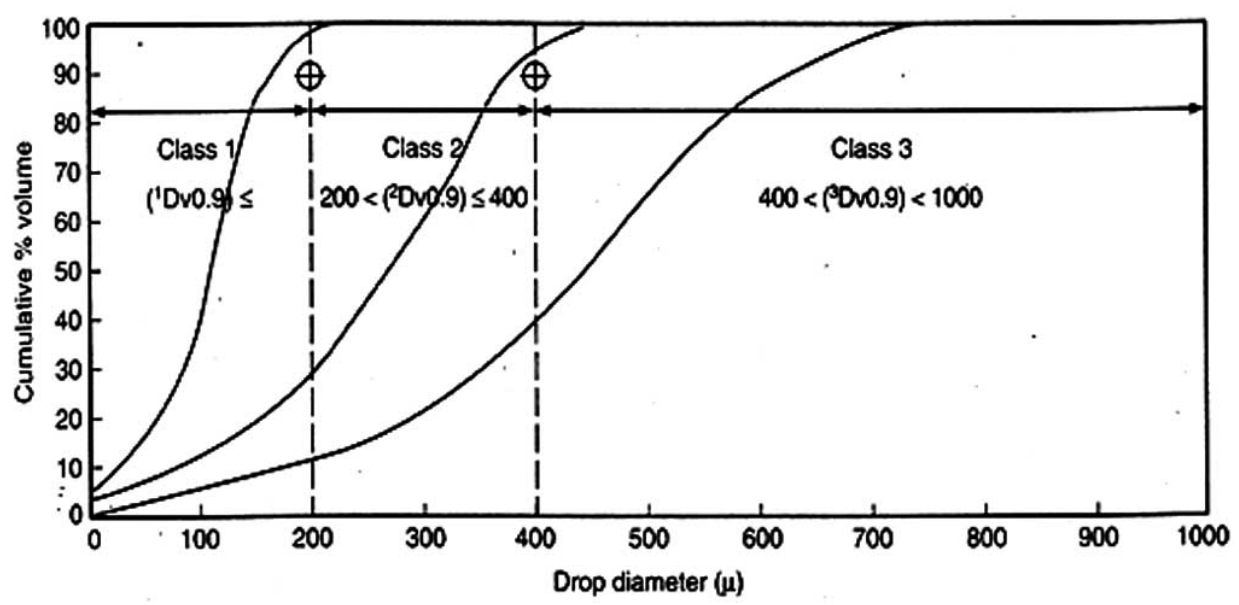

Fig. (1). Drop Size vs. Volume-Fraction Distribution and NFPA 750 classification [3].
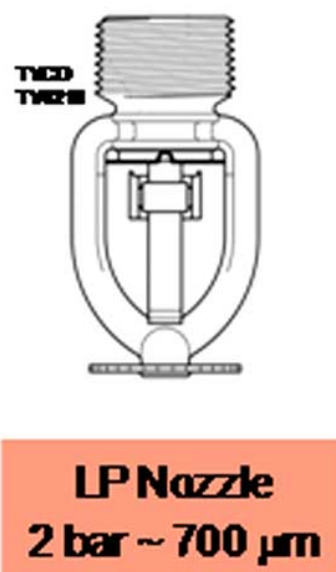
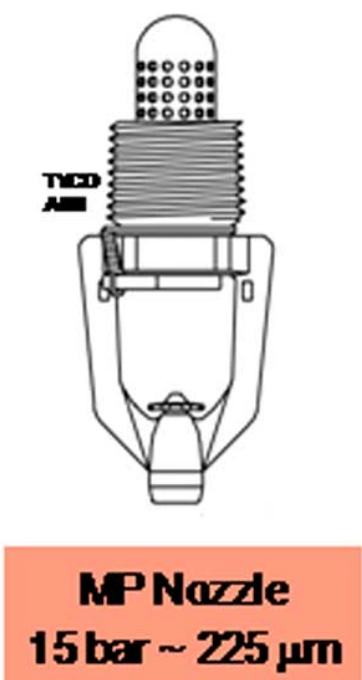

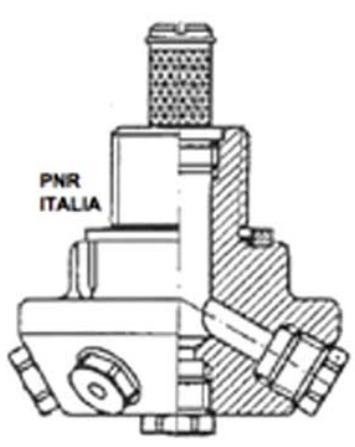

HPNozale 100 bar

Fig. (2). Sketches of typical nozzles employed in fire protection with respect to operative pressure, together with some estimation of the characteristic $\mathrm{D}_{\mathrm{v} 50}$.

Strong initial jet momentum is achieved by high working pressure: this physical consequence represents another important feature of water-mist sprays. Buoyancy phenomena certainly occur in highly atomized jets because of the tiny drop size, but once a main share of the spray is momentumdriven, penetration in the surroundings is provided. Otherwise, droplets would simply float and interact with surrounding air: fire quenching would be performed through heat absorption, but no fire suppression would be realized due to absence of flow-flame interaction. Producing tiny droplets with strong momentum also allows to penetrate potential enclosures: this is a major challenge for any fire-protection system.

Despite many efforts are still required to gain a comprehensive knowledge on water-mist systems, some studies are available in the open literature and are surveyed in the present paper. As introductive works, it is worthwhile to mention some contributions aimed at providing a broad overview on water sprays in fire-protection with some emphasis on water mist. First and foremost, the early researches conducted by Rasbash and co-workers [4,5] on extinguishment of liquid fires by water sprays deserve to be cited as one of the first reference in the field. These studies constitute the cultural background for a recognized work performed by Grant et al. [6]. It consists of a thorough review about water sprays applied to fire suppression: the standard fire classes are listed and their features are described; then, different spray-based technologies are surveyed and thoroughly discussed. The authors report a drop-size-based definition of water mist and discuss its suitability to face particular fires. In addition, detailed guidance is given to system designers about practical subjects like nozzles or pipes. Finally, it is noteworthy to mention the authors' deep insight of heat transfer, jet formation and spray pattern: these are fundamental physical phenomena and have to be quantitatively evaluated to properly configure any spray system for a fire scenario.

Notarianni [7] has carried out a remarkable practical study in the frame of the NFPA (National Fire Protection Association) activity towards a regulation on water mist. This work represents one of the first reference in this field and it is of great interest for industries and engineers: the author has collected a number of technical data to set water- 
mist systems in a precise branch of fire suppression and has also provided a list of research groups working on this subject. This study represents a firm background and has served as one of the keystones to propose and then issue a standard on water-mist technology.

\section{HEAT TRANSFER AND SUPPRESSION MECHA- NISMS}

Water-mist spray is generally characterized by a large surface-area-to-volume ratio; therefore, a higher rate of heat and mass transfer results as the water-mist flow is injected into a hot surrounding fluid. This effect plays a major role in determining heat-release and smoke-production rate; moreover, smoke movement also is strongly affected by the above mentioned thermal transport. A set of physical relations is presented in this section to describe both heat transfer and suppression process; a thorough discussion about the involved mechanisms has also been shown in previous reviews on water-mist systems, proposed by Mawhinney and Richardson [8], Liu and Kim [9] and Yao and Chow [10]. The set of equations here reported is in deep surveyed in those works and in the early fundamental study by Jones and Nolan [11].

Fire suppression consist of three main physical effects: evaporation cooling, oxygen displacement and radiation blocking.

The first one is related to latent heat of water evaporating from liquid to gas phase. This amount of energy is up to 2.26 $\mathrm{MJ} \mathrm{kg}^{-1}$. A water-mist discharge onto burning objects cools down both flames and plume. Heat, mass and momentum transfer between a generic water droplet and the surrounding hot gas may be calculated through the following equations:

$$
\begin{aligned}
& m_{d} c_{p d} \frac{\mathrm{d} T_{d}}{\mathrm{~d} t}=h A_{d}\left(T_{g}-T_{d}\right)+m_{d} q_{e}, \\
& \frac{\mathrm{d} m_{d}}{\mathrm{~d} t}=A_{d} h_{m}\left(\frac{p_{s}\left(T_{d}\right)}{R T_{d}}-x_{v} \frac{p_{g}}{R T_{g}}\right), \\
& \frac{\mathrm{d} \vec{V}_{d}}{\mathrm{~d} t}=-\frac{3}{4} \frac{\rho_{g}}{\rho_{d}} \frac{C_{D}}{d}\left(\vec{V}_{d}-\vec{V}_{g}\right)\left|\vec{V}_{d}-\vec{V}_{g}\right|+\frac{\rho_{d}-\rho_{g}}{\rho_{d}} \vec{g} .
\end{aligned}
$$

In Eqs. (1), (2) and (3), $m_{d}, c_{p d}, A_{d}$ and $q_{e}$ are mass, specific heat, surface area and latent heat of the water droplet respectively; $T_{d}$ and $T_{g}$ are the temperatures of the droplet and of the hot gas; $x_{v}$ is the molecular fraction of water vapor within the gas; $R$ is the ideal gas constant; $p_{g}$ is the gas pressure and $p_{s}\left(T_{d}\right)$ is the saturated vapor pressure at droplet temperature; $V_{d}$ and $V_{g}$ are velocity of the droplet and of the hot gas respectively; $\rho_{d}$ and $\rho_{g}$ are the density of the droplet and of the hot gas respectively; $d$ is the droplet diameter; $C_{D}$ is the drag coefficient and $g$ is gravity acceleration.

The convective heat-transfer coefficient $h$ and the masstransfer coefficient $h_{m}$ may be simply evaluated through Nusselt, $N u$, and Sherwood, $S h$, dimensionless quantities. To the purpose, common correlations referred to the sphericaldroplet case can be employed:

$$
N u=\frac{h d}{k}=2.0+0.6 \operatorname{Re}_{r}^{1 / 2} \operatorname{Pr}^{1 / 3},
$$

$$
S h=\frac{h_{m} d}{D}=2.0+0.6 \operatorname{Re}_{r}^{1 / 2}\left(\frac{v_{g}}{D}\right)^{1 / 3}
$$

where $k$ is thermal conductivity of gas phase; $D$ is mass diffusivity; $R e_{r}$ is a "relative" Reynolds number, that is based on the relative velocity between droplet and gas phase; $\operatorname{Pr}$ is the Prandtl number and $v_{g}$ is kinematic viscosity of the gas phase.

Droplets characterized by small diameter and high relative velocity are rapidly heated by convection and then evaporate $[6,12,13]$. As a common classical reference $[6,12]$, if the flame temperature is $1000{ }^{\circ} \mathrm{C}$, the droplet diameter is $150 \mu \mathrm{m}$ and the spray velocity is $2.5 \mathrm{~m} \mathrm{~s}^{-1}$, water droplets evaporate after an average penetration of just $90 \mathrm{~mm}$ into the flame. This evaluation is funded on the assumption of water droplets heated up from ambient temperature to $373 \mathrm{~K}$ before evaporation (even though some proper mist tends to evaporate before reaching $373 \mathrm{~K}$ ). Moreover, water vapor is considered to be heated up from $373 \mathrm{~K}$ to the flame temperature of $1273 \mathrm{~K}$. If density of the water flux is $2.01 \mathrm{~m} \mathrm{~s}^{-1}$ and ambient temperature is $293 \mathrm{~K}$, the heat-extraction rate due to vaporization is $75 \mathrm{~kW} \mathrm{~m}^{-2}$, if latent heat of water evaporation is taken as $2.26 \mathrm{MJ} \mathrm{kg}^{-1}$. The heat-extraction rate to heat up water droplets and vapor is 11.2 and $72 \mathrm{~kW} \mathrm{~m}^{-2}$ assuming their specific heat as 4.2 and $2.4 \mathrm{~kJ} \mathrm{~kg}^{-1} \mathrm{~K}^{-1}$ respectively. Therefore, the maximum total heat-reduction rate is 160 $\mathrm{kW} \mathrm{m}{ }^{-2}$. As expectable, decreasing droplet diameter and increasing droplet velocity provides an increase of evaporation effectiveness.

With regard to oxygen displacement, the combustion rate of a fire $R_{f}$ depends on temperature and mass fraction of the reactants. The Arrhenius finite reaction-rate model is useful to evaluate $R_{f}$ :

$$
R_{f}=-A \rho^{\alpha+\beta} m_{f}^{\alpha} m_{o x}^{\beta} \mathrm{e}^{-E / R T},
$$

where $A, \alpha$ and $\beta$ are empirical constants; $\rho$ is the fluid density; $m_{f}$ and $m_{o x}$ are mass fractions of fuel and oxygen respectively and $E$ stands for the activation energy of the chemical reaction.

$R_{f}$ decreases if temperature is reduced because of cooling, together with a lower heat release. If the water vapor generated from mist increases, air is displaced inside regions within or close to the fire and oxygen concentration is reduced. As the final result, this mechanism would extinguish the fire or at least reduce the heat-release rate.

When gaseous fuels such as methane are involved in the fire, the reaction is constituted by one single step and is irreversible: the model constants $\alpha$ and $\beta$ could be taken as 1 . A large number of diffusion flames and deep-seated fires would extinguish if the ambient oxygen concentration stands below $13-15 \%$ and $8 \%$ respectively, as stated by Back III et al. [14]. The vapor amount in saturated air at temperature above $353 \mathrm{~K}$ is sufficient to dilute oxygen concentration below the limit value for most fuels.

The last considered heat-transfer phenomenon is radiation blocking. Radiant heat transfer from high-temperature flames and hot smoke layers to the surrounding objects is blocked by fine water droplets as a result of absorption and 
scattering. This effects mainly prevents the fuels from volatizing and burning, but also reduces the fire-growth rate and fire spread. Moreover, it increases the time to flashover in a compartment.

The transmitted spectral flux $q_{\lambda}$ in a monodisperse water spray is yielded by the following relation [15], when referred to a path length (spray thickness) $L$, water load $M$ and droplet diameter $d$ :

$$
q_{\lambda}=E_{\lambda T} \frac{2 \gamma e^{-\gamma \tau}}{w(1-f) R_{t}\left(e^{-2 \gamma \tau}-1\right)+1-w k_{e x t}+\gamma+(\gamma+w f-1) e^{-2 \gamma \tau}},
$$

where $k_{\text {ext }}$ is the extinction coefficient $\left(Q_{\text {ext }} / L\right) ; w$ is the albedo of a generic droplet (ratio between diffusion efficiency $Q_{d i f}$ and extinction efficiency $\left.Q_{e x t}\right) ; R_{t}$ is the reflection factor of a target; $\tau$ is the effective extinction coefficient; $f$ is the angular dissymmetry factor and $E_{\lambda T}$ is the emissive power of a black body. $\gamma, k_{\text {ext }}$ and $\tau$ can be expressed as follows:

$$
\begin{aligned}
& \gamma=\sqrt{(w f-1)^{2}-w^{2}(1-f)^{2}}, \\
& k_{e x t}=\frac{6 M Q_{e x t}}{4 \rho d} \\
& \tau=k_{e x t} L .
\end{aligned}
$$

The fraction $r$ of total heat flux transmitted through water spray is determined as the share represented by the total transmitted flux $q_{t r}$ :

$$
r=\frac{q_{t r}}{E_{T}}
$$

where $q_{t r}$ is obtained integrating $q_{\lambda}$ over the whole range of wavelength:

$$
q_{t r}=\int_{0}^{\infty} q_{\lambda} \mathrm{d} \lambda
$$

The maximum blocking of thermal radiation is achieved if droplet diameter has the same order of magnitude as the maximum emission wavelength of the fire source [15]. For example, if a water spray load of $100 \mathrm{~g} \mathrm{~m}^{-3}$ is considered, together with a diameter $D_{v 10}$ of $100 \mu \mathrm{m}, D_{v 90}$ of $200 \mu \mathrm{m}$ and a path length of $1 \mathrm{~m}$, about $60 \%$ of the radiant heat from a black body at $1073 \mathrm{~K}$ would be blocked [15]. If a fire is assumed as a black body at about $1300 \mathrm{~K}$, the maximum emission length would be $1.93 \mu \mathrm{m}$ and $95 \%$ of the total energy would be radiated in the wavelength range between $1 \mu \mathrm{m}$ to $10 \mu \mathrm{m}[6,16]$. Radiant heat blocking plays a major role with relation to water droplets having diameter lower than $30 \mu \mathrm{m}$.

The above mentioned three mechanisms have the main impact on suppression effectiveness of a water-mist system. However, some other effects should be reported as additional phenomena to that related: fuel-surface wetting and cooling prevent fire spread and potential saponification of additives such as alkaline mixtures is employed to fight re-ignition. The water vapor generated from mist shows chemical effects on soot and radical formation, providing some changes in thermal radiation and combustion processes: these phenomena are significant with high-temperature diffusion flames [17]. Other effects as expansion mixing at certain thermal conditions increase smoke and toxic-gas generation [18]. However, suppression is the main phenomenon if water-mist systems are properly designed to discharge sufficient volume flux onto and within the flames.

\section{FLUID DYNAMICS OF WATER-MIST SPRAYS: ATOMIZATION AND DISPERSION}

As a common approach to fluid dynamics of sprays, two phenomena are identified to provide a fundamental characterization of the flow: atomization and dispersion. However, a second step is sought to quantitatively express them: a set of parameters is typically investigated to evaluate both the former and the latter. Drop-size distribution, water-flux density, spray-cone angle and droplet velocity are these key features of any spray: the first one clearly represents the atomization degree, while the others are more related to dispersion phenomenon, even if they may provide some indirect information about atomization as well. The mentioned set of parameters also has a direct connection to suppression mechanisms; on the other hand, other characteristics as compartment geometry, ventilation conditions and fuel properties constitute the external factors. In case of a specific reference to water-mist sprays in fire-suppression, the whole multiphase flow is made up by dispersed droplets, generated vapor, fire-induced air flow and spray-induced air flow. Multiphase fluid dynamics strongly affects fire-suppression performances and it may be described through the classical relations on mass, momentum and energy conservation for each phase [19].

Droplet trajectory and evaporation rate are mainly governed by the interaction between the sprayed flow (droplets) and the surrounding fluid: this includes momentum, mass and heat transfer. These phenomena are significantly affected by dynamics of the fluid flow, that means velocity and temperature, together with the fluid properties (i.e.: viscosity and density). Fire suppression is basically governed by the above mentioned mechanisms. In terms of fluid mechanics, the main forces acting on the droplets are inertia, air drag and buoyancy. Moreover, other force typologies such as the ones related to virtual mass effect and the Basset force might be taken into account if significant [19]. The heat amount transferred from hot fluids to water droplets through forced convection generates water vapor on the droplet external surface: it is subsequently transported and dilutes oxygen concentration. The conservation equations on momentum, heat and mass transfer (see section 2) present drag coefficient, convective heat and mass transfer coefficients as the key parameters governing heat and momentum transfer among water droplets and the surrounding fluid flows. As already mentioned in section 2, many of these parameters are correlated with non-dimensional quantities such as the "relative" Reynolds, Prandtl and Schmidt numbers [19]. The "relative" Reynolds number represents a sort of basic factor having a remarkable impact on momentum-, heat- and masstransfer processes. As a straight connection, larger transfer rates result in an increase of the "relative" Reynolds number.

Another phenomenon significantly affecting the momentum, heat and mass transfer is fluid turbulence. Fundamental studies on the effect of relative turbulence intensity have yielded some quantitative insight on the relation between turbulence and transport mechanisms [19]. At lower Rey- 
nolds numbers, the Nusselt number shows a rapid increase as the turbulence intensity is up to $1 \%$; as this latter grows beyond this value, a linear relation appears to occur. At higher Reynolds numbers, the linear variation of Nusselt number with turbulence intensity seems to be consistent with the values for flows with no turbulence. A considerable discrepancy is reported among the numerous data on the dependence of drag coefficient on turbulence. Therefore, experimental studies are still required to provide a more effective comprehension on turbulence effects. However, the developed drag curves may be of some interest for droplets in subcritical turbulent flow. As a final remark, additional correlations are sought for flows at critical and supercritical Reynolds number: an increase of relative turbulence intensity implies a decrease of the critical Reynolds numbers. At a given relative turbulence intensity, the drag coefficient grows with the length-scale ratio, that is turbulence macroscale over droplet characteristic diameter [19]. Therefore, smaller droplets appear to be more sensitive to fluid turbulence than larger droplets. This final fundamental outcome seems to imply that turbulence models developed for traditional-sprinkler sprays might not be thoroughly applicable to the water-mist case.

Some brief remarks are required on fluid dynamics of diffusion flames, as far as they represent the usual element of interaction with water-mist droplets. The finite chemicalreaction rate in a diffusion flame is affected by the concentration of fuel vapor and oxygen. If continuum media are considered, water vapor generated from droplets is transferred by the turbulent flows to the room: therefore, a reduction of oxygen concentration is provided. A convenient description of these turbulent motions can be performed through a k- $\varepsilon$ model in CFD (Computational Fluid Dynamics) analyses. However, if high temperatures of the surrounding fluid are reached, another phenomenon occurs to limit the chemical-reaction rate: turbulent mixing of the reactants, which may be represented by eddy-breakup models [20] in numerical simulations.

The major role played by fluid dynamics in water-mistbased fire suppression is particularly evident for smaller droplets. For instance, if referring to large fires, plume velocity and temperatures are higher, so water mist of smaller diameters or velocity may not be able to penetrate the plume and reach the flame. Water droplets may evaporate into vapor or be dragged away by the plume-induced air flow [21]. In some cases, water mist suspended in the air might be entrained into the fire-induced flow and suppress the fire: the density flux of entrained water mist is determined through the fluid (air)-transport capability. Therefore, drop size appears to be a key parameter to understand control and suppression effectiveness and different drop-size families may play different roles with respect to both heat transfer and dynamics within the fire scenario. In spite of the importance of characterizing water-mist sprays, very few works have been conducted to this end. Among them, it is worthwhile to mention the extensive studies carried out by Paulsen Husted [22], Paulsen Husted et al. [23], Santangelo et al. [24,25] and Santangelo [26]. These works have been focused on a pure characterization of water-mist sprays in terms of atomization and dispersion following experimental, theoretical and numerical approaches. Drop-size distribution has been determined employing laser-based techniques as PDPA (Phase Doppler Particle Analyzer) and Fraunhofer diffraction (the well recognized Malvern Spraytec device). Appropriate methodologies have been ad hoc developed to post-process experimental data and reconstruct the overall drop-size distribution. Fig. (3) reports a common release of this parameter with respect to volume fraction of the spray. Moreover, distribution functions and correlations have been conveniently validated to predict drop-size trend and characteristic spray

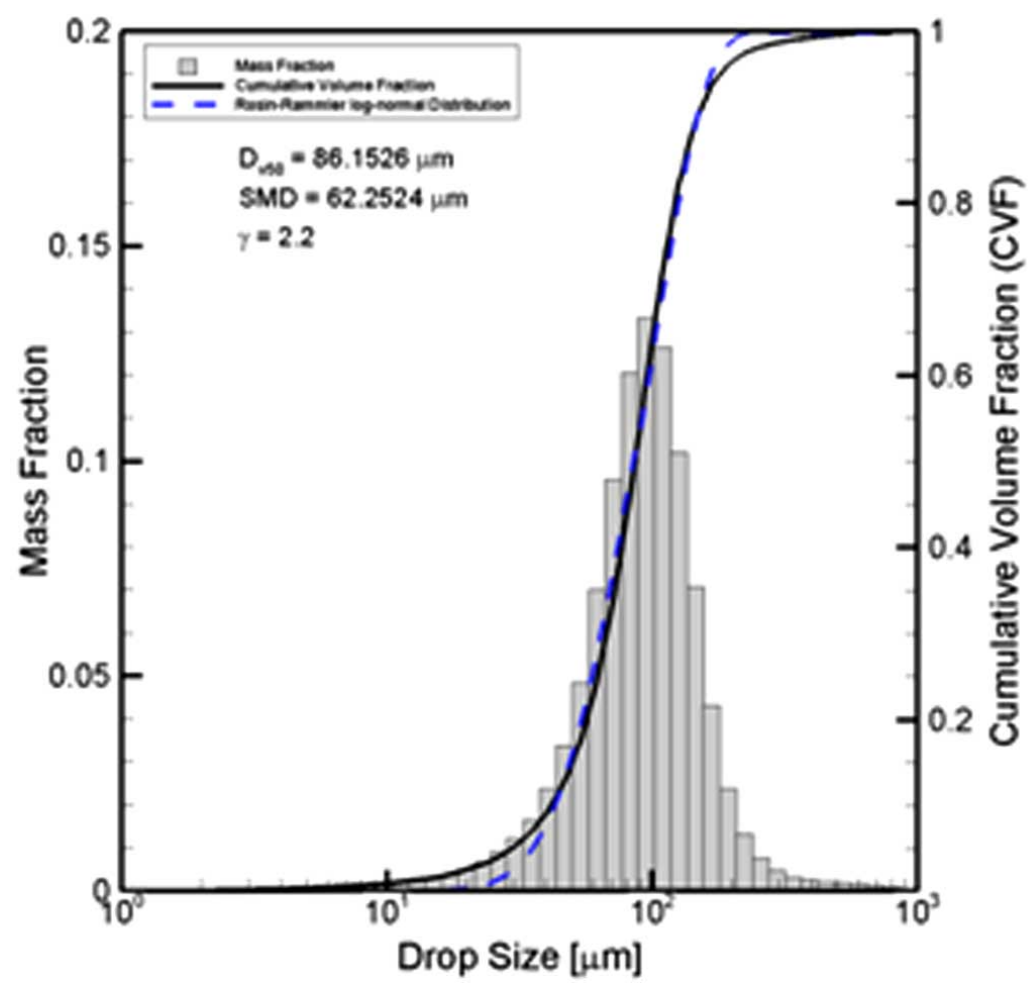

Fig. (3). Typical reconstructed Drop Size vs. Cumulative Volume Fraction curve (operative pressure of 80 bar) [24,26]. 
diameters. Velocity and spray-cone angle have been investigated as well mainly through PIV (Particle Image Velocimetry) campaigns. Fig. (4) is a representative sketch of a PIV test rig for high-pressure water-mist sprays, as it was employed by Paulsen Husted et al. [23] to run a comparison between PIV and PDA (Phase Doppler Anemometry) measurements in terms of velocity. In addition, Fig. (5) shows a PIV map of a water-mist spray: velocity magnitude is here presented as a contour plot together with vectors expressing the spray trajectory. It is finally noteworthy to emphasize the importance of experimental and theoretical studies on fluid dynamics of water-mist sprays, because of the need for validated models to that related. These models constitute a required input for numerical codes aimed at simulating the entire fire-suppression process, being a realistic representation of spray dynamics the key to properly predict flowflame interaction. Some numerical works are available on this subject in the open literature [22,25]. Among them, a remarkable study has been performed by Trelles et al. [27]. This work thoroughly focuses on the spray characterization and simulation. The authors stress out the importance of gaining a detailed and reliable characterization of the water spray; then, this latter has to be simulated showing good agreement with test cases. The proposed analysis is related to a multi-orifice nozzle operating at high pressure (greater than 70 bar). Drop-size distribution was a priori known from previous measurements, as well as geometry of the nozzle and flux-density distribution one meter below the nozzle. This latter information is used as a validating tool to verify the predictive capabilities of the computational code. The proposed approach is very similar to the one featuring other works $[22,25]$. FDS (Fire Dynamics Simulator) by NIST (National Institute of Standards and Technology) has been employed to run the numerical tests; as already mentioned about other works [22,24-26], a distribution function has been applied to model drop sizes. Although the input velocity value is questionable because no background information is given about it, results appear qualitatively encouraging: the mass-flux map is reasonably reconstructed when the grid spacing is fine. However, as this parameter becomes too large (resolution equal to roughly $150 \mathrm{~mm}$ ), droplet trajectories are lost and mass-flux distribution is not properly reproduced.

Finally, at least a brief comment on CFD is nowadays strongly required when discussing fluid dynamics of any physical phenomenon. As already stated, it can be employed to study flow-flame interactions and suppression mechanism for given fire scenarios: the available results are surveyed in section 4; however, they may lack accuracy as the effects of turbulence, combustion and evaporation have to be taken into account at the same time. However, an important feature of CFD data is to serve as a quantitative comparison among fire-suppression process by different water-mist systems. This approach is characterized by a relatively low cost, especially if compared to experimental tests, so it is of interest for designers in selecting the most suitable system for a given configuration with respect to performance-based criteria.

\section{EXPERIMENTAL AND NUMERICAL STUDIES}

Many efforts are still needed to profoundly investigate fundamental aspects and technical functioning of water-mist technology with respect to a variety of fire scenarios. In particular, extensive researches are required to gain a proper comprehension of the main physical phenomena: discharge, fire control and potential suppression. In addition, the available predictive tools lack general reliability, being them usually realized and validated for specific cases or configurations. However, the open scientific literature already shows some contributions aimed at enhancing both researchers' and practitioners' knowledge in the field: a critical overview of studies and achievements is here presented.

\subsection{Fundamentals of Extinction and Flow-Flame Interac- tion}

Fire control and suppression by water mist is strongly related to the interaction between the sprayed flow and the flames. This general physical phenomenon has been investigated employing the numerous theoretical relations on combustion processes coupled to classic heat-transfer equations applied to the droplets. Many parameters are involved to gain a quantitative evaluation on extinction and suppression: first and foremost, temperature decay within the fire zone; heat release rate; heat dissipation and burning velocity. However, even though this set of parameters is physically significant, but should be linked to other features to provide guidance for system design. To the purpose, extinction and flow-flame interaction has been finally correlated to drop size, as the key characteristic of any spray. For instance, the large body of numerical works implements the already men-

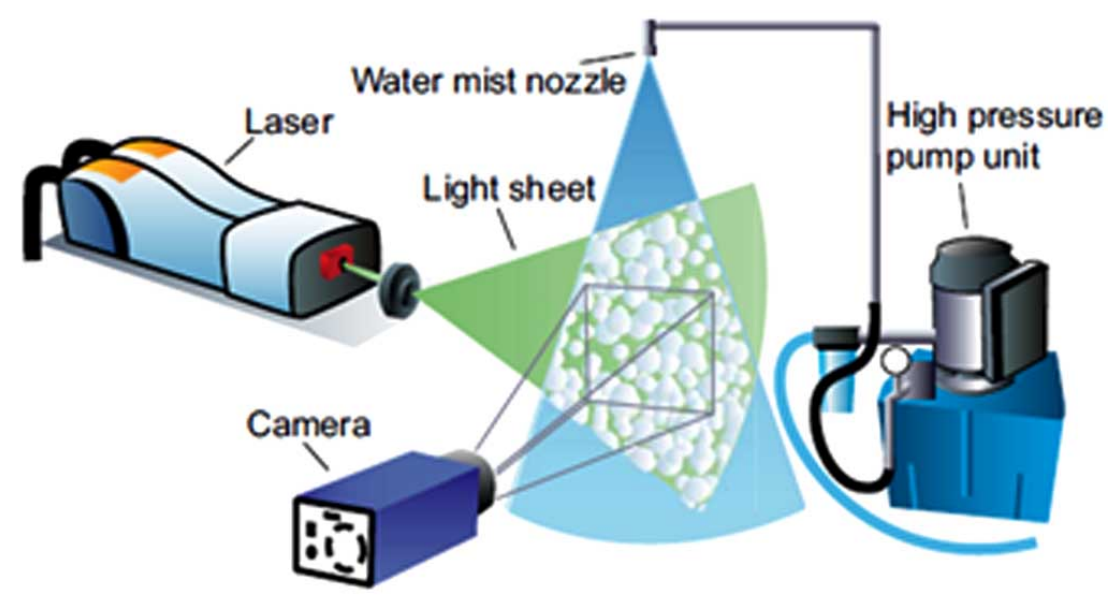

Fig. (4). Sketch of the PIV test rig developed by Paulsen Husted et al. [23]. 


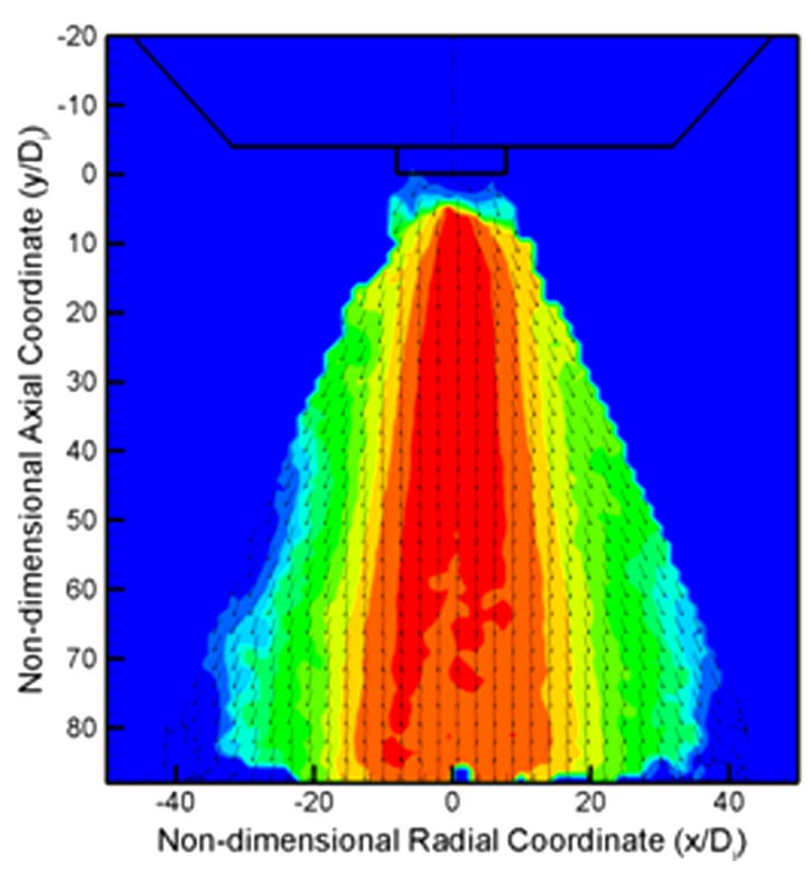

Fig. (5). Reconstructed PIV map of a water-mist spray (operative pressure of 80 bar); coordinates are conveniently made nondimensional through a ratio by the internal orifice diameter $[25,26]$.

tioned equations, but mainly shows the ultimate aim at determining the suppression trend as a function of droplet characteristic diameter. As an additional remark, the high complexity of flow-flame interaction has brought to conduct very few experimental researches, even because of the high costs related to fire tests, being them small- or full-scale.

One of the first scientific works on water mist has been realized by Ndubizu et al. [28]: the Naval Research Laboratory was one of the first institutions to show interest in water mist as a fire-protection system for both shipboard and residential applications. The authors stress out the importance of this technology as an alternative to the banned halon-based and they focus on gaining a full comprehension of suppression mechanism of a two-dimensional gaseous diffusion flame. The experimental side of this study has been performed employing a Wolfhard-Parker burner: the fuel slot is $10 \mathrm{~mm} \times 150 \mathrm{~mm} \times 75 \mathrm{~mm}$, while the two oxidizer channels are $35 \mathrm{~mm} \times 150 \mathrm{~mm} \times 82 \mathrm{~mm}$. Temperature drops have been measured in a methane flame subjected to a nitrogen, steam and water-mist co-flow. Moreover, a theoretical model is proposed to discuss heat generation and loss occurring to flames when suppressants are introduced. The main result of this work consists of an evaluation of the suppression effectiveness (degree of suppression) as concentration of the three components varies. This result is sketched in Fig. (6), where suppression effectiveness is quantitatively represented by a non-dimensional temperature drop $\left(\mathrm{T}_{0}\right.$ is the adiabatic-flame temperature).

As expected, water mist appears to provide a more efficient suppression: a thorough discussion is presented about the gas-phase cooling effect as one of the key phenomena to physically perform fire suppression. This effect is basically due to latent heat and heat capacity, that is higher in water vapor compared to air. Moreover, another additional outcome is shown: oxygen dilution by water mist appears to be of lower importance than the other mentioned effect. The authors also have attempted an investigation on the role played by these two phenomena with respect to characteristic drop size, that has been measured employing a Malvern Spraytec particle sizer where droplets leave the oxidizer in the Wolfhard-Parker burner.

Almost the same subject has been investigated by Fisher et al. [29], in the frame of the long-term research promoted by the US Navy. Suppression effectiveness of non-premixed propane-air flames by fine water mist has been experimentally analyzed (Fig. (7)). Water droplets have been produced by a piezoelectric generator with a mean size lower than 10 $\mu \mathrm{m}$. Extinction experiments have been carried out with flow rates of $0.211 \mathrm{~min}^{-1}$ for propane and $381 \mathrm{~min}^{-1}$ for the whole oxidizer stream. As a result of a comparison between water mist and nitrogen in extinguishing this fire, it is shown that $66 \%$ of the total enthalpy of mist brings to flame suppression. PIV has been employed to visualize mist evaporation, flow-flame interaction and droplet trajectories. Evaporation is shown to occur primarily outside the flame and then water

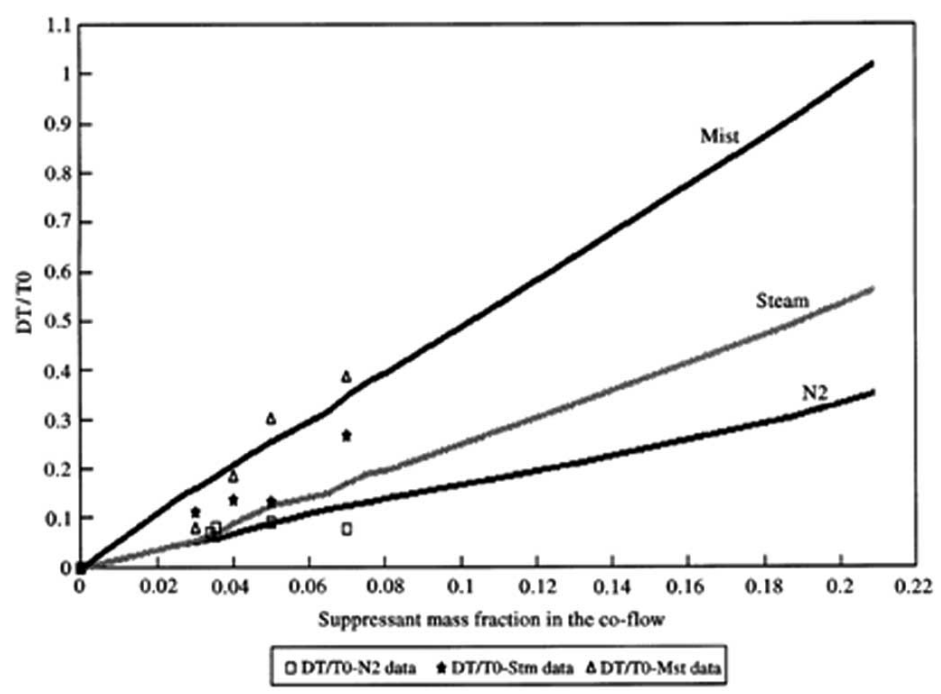

Fig. (6). Degree of suppression at various concentrations of nitrogen, steam and water mist: theoretical curves and experimental data [28]. 


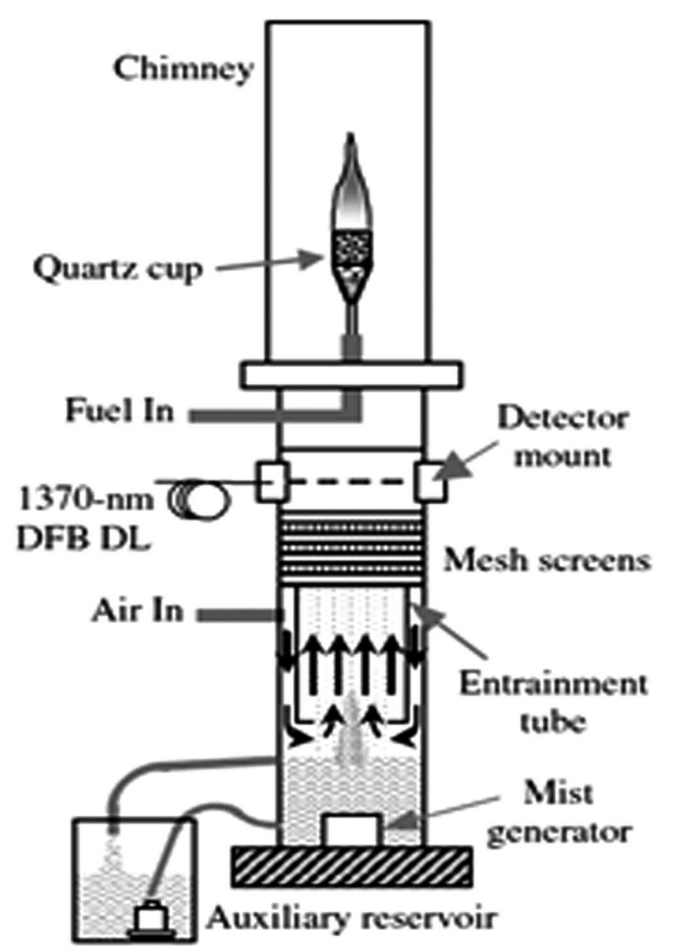

Fig. (7). Cup burner apparatus to visualize interaction between propane/air non-premixed flames and a water-mist flow. Optical instruments are not represented in this sketch [29].

vapor tends to follow an entrainment motion along with the air flow. The authors suggest that flames are subjected to only a portion of the cooling effect due to drop evaporation. Evaporating droplets exchange heat with the incoming water-mist bulk and they provide extinction more as a heat sink than as a proper suppressant. This explanation is also proposed in Thomas [30], concerning the smaller droplets in the water-mist distribution.

The Naval Research Laboratory also has recently coupled the experimental to computational simulations in the frame of an extensive research supported by the US Navy to investigate the most innovative water-mist configurations. Adiga et al. [31] have aimed their study at analyzing performance of ultra-fine water mist (drop size lower than $10 \mu \mathrm{m}$ ): this work appears to be strongly connected to the one previously mentioned [29] about suppression effectiveness. The experimental campaign has been carried out in a large compartment with a heptane pool fire. Tests have been performed in a typical cubic steel-walled compartment $\left(28 \mathrm{~m}^{3}\right)$, where heptane fires with $5 \mathrm{~kW}$ and $120 \mathrm{~kW}$ of heat release rate have been set. In addition, a $70 \mathrm{~kW}$ methanol fire also has been used. An ad hoc developed experimental facility has been used to perform tests and gain quantitative data about the thermal transient at a number of locations within the fire scenario. The mist has been produced by an ultrasonic generator: this technology is very innovative and does not employ traditional injectors. The imposed momentum is very low and the discharge velocity is below $1 \mathrm{~m} \mathrm{~s}^{-1}$ : the difference between this spray and a commonly injected one is evident even in terms of classical dynamics parameters. Mist has been spread as a total flooding agent inside the com- partment. With regard to the computational side, Fluent ${ }^{\circledR}$ by ANSYS Inc. has been employed as the CFD code to run calculations on mist-flame interaction and suppression time. A Lagrangian discrete-phase model has been applied to simulate droplet behavior. Strong discrepancies have arisen about extinction-time scale between CFD predictions and experimental results; however, a better agreement has been found by modeling the water mist as a dense gas. As a final observation, a multi-phase Eulerian approach together with a vaporization model is stated to be in demand to gain a proper evaluation of mist-flame interaction. Santangelo et al. [25] have pointed out similar difficulties in predicting a spray dispersion in water-mist flows through Fluent ${ }^{\circledR}$-based models.

As already stated, numerical predictions of spray flows still need to be improved in terms of both dynamic behavior and droplet formation. This challenge is even more remarkable for water-mist sprays, where a large number of extremely fine droplets leads any modeler to face statistic problems to discuss atomization and dispersion phenomena. Despite this need for fundamental improvements on the fluiddynamic side, a considerable body of numerical studies has been conducted over the last decade to predict the interaction between a water-mist flow and flames. These works mainly implement combustion models coupled to heat-transfer equations to predict the suppression mechanism.

In the frame of these researches, theoretical and numerical approaches have been employed by Chelliah and his coworkers throughout their studies on the interaction between water mist and flames, that is investigated through its fundamental physical aspects. Lentati and Chelliah [32] have focused their efforts on simulating the extinguishing process of laminar counterflow non-premixed flames by tiny watermist droplets. These latter have modeled over several monodisperse sizes in the range $5-50 \mu \mathrm{m}$. To this end a novel hybrid Eulerian-Lagrangian method has been applied to model the two-phase flow constituted by gas and droplets. In particular, the Lagrangian approach overtakes singularities arising with the droplet-density equation: these singularities can be hardly solved by a numerical code. Chemical kinetics has been fully modeled, while droplet evaporation and heat transfer have been treated under steady-condition assumption. This model has been implemented in a computational code; a non-monotonic dependence of flame extinction on drop size has been stressed out: this unexpected result appears to be due to drop dynamics in a counterflow field. This contribution appears to be the most significant, because it stresses out a non-uniform behavior of water mist as dropsize varies in terms of suppression. The mentioned outcome is concisely sketched in Fig. (8), where a stoichiometric dissipation-rate coefficient $\left(\chi_{s}\right)_{\text {ext }}$ is introduced to evaluate heat transfer between water droplets and flames: as a matter of fact, this parameter is the inverse of diffusion time scale.

In a later work, Chelliah [33] has studied the drop-size optimization to suppress or at least inhibit methane-air flames: this approach appears to enhance the previous results [32] and refer to a particular flame typology. Resident time of both laminar premixed and counterflow non-premixed flames has been employed to model the combustion phenomena. Resident time of the former is shown to be governed by droplet trajectory, while resident time of the latter is strongly connected to the convective-diffusive layer of the 


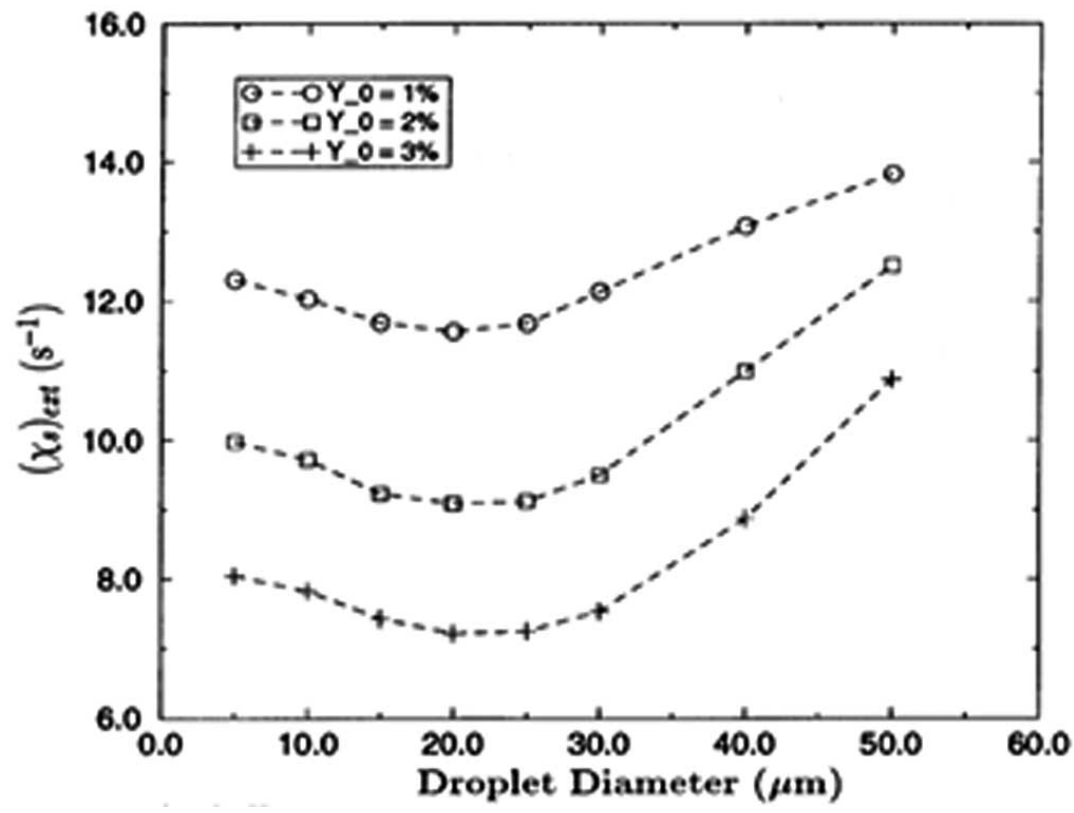

Fig. (8). Comparison of scalar dissipation rate with respect to drop size for different droplet mass fractions [32].

air stream. No velocity lag is assumed between droplets and gas. The proposed predictive model yields to two optimal drop-size values: $6.5 \mu \mathrm{m}$ for premixed flames and $20 \mu \mathrm{m}$ for non-premixed. Chelliah has also carried out numerical simulations based on the developed theory and he has found that the commonly accepted linear relation between flamestrength decrease and specific drop surface area is valid only if drop size is greater than the optimal value. Once drop size becomes close to the optimal value, thermal and chemical effects change and lead to a non-linear relation (Fig. (9)). Note that drop size is here expressed by the surface-area parameter, that is the ratio between drop concentration $\left(Y_{0}\right)$ and drop diameter $\left(d_{0}\right)$. Moreover, flame strength is made nondimensional through a ratio by either square of burning velocity $\left(S_{L, v a p}{ }^{2}\right.$, for premixed flames), or extinction conditions ( $a_{\text {ext,vap}}$, for non-premixed flames). This outcome is of great interest in designing water-mist systems, especially if limited amount of water is available.

Another important numerical study on quenching effect of water mist on methane-air flames has been conducted by Thomas [30]. The author investigates the limit value for droplet and vapor concentration to prevent laminar flames self-sustaining their propagation. Chemical kinetics, gas dynamics and thermal effects have been physically modeled and droplet transient evaporation has been evaluated through an approximate approach, that is based on mass, energy and momentum transfer between the two phases. The author seems to have the same aim as Chelliah [33]: achieving a trend of extinction with respect to drop size and providing a sort of optimized value. Thomas states that $10 \mu \mathrm{m}$ is a critical value for drop diameter: smaller droplets evaporate too early to show a significant influence on the flames. This result is represented in Fig. (10), where burning velocity is taken as the key parameter to quantify quenching and extinction. As drop size decreases, a higher density of droplets is required to yield the same burning-velocity reduction and 10 $\mu \mathrm{m}$ is identified as a numerical limit to simulate the suppression mechanism. However, smaller droplets may play a remarkable role as water vapor within the pre-heat region.
The author also proposes a set of suitable loading densities in respect to different drop sizes greater than the above mentioned limit value. Kinetic inhibition of chemical reactions appears to be the most effective quenching mechanism, as far as thermal effects are not sufficient for flame control: an additional task of Thomas' research is to verify inhibition when alkali salts are added to flames. This case recalls a pure chemical extinction mechanism. However, salt addition becomes more ineffective the higher is the mean drop diameter. As a final outcome, extinction seems to be most performed by droplets of diameter lower than $50 \mu \mathrm{m}$ (Fig. (10)) and the range $10-30 \mu \mathrm{m}$ is the one that needs to be particularly characterized.

Recent enhancements about extinction effectiveness of premixed methane-air flames by water mist have been brought in by Parra et al. [34] from a purely numerical point of view. The authors focus on a one-dimensional model, where the water flow is subjected to the following subsequent phenomena: dragging, breakup, heating and vaporization. The computational domain is confined and discretized with adaptive meshes; its size is $12 \mathrm{~m} \times 1.2 \mathrm{~m}$. The initial temperature of the cold gases is $300 \mathrm{~K}$, while the hot-spot ignition is simulated imposing $1800 \mathrm{~K}$ as the temperature of the hot side within the domain. Chemical kinetic reactions occurring in flow-flame interaction are taken into account. The highest contribution of this work consists of considering both deflagration and detonation as propagation regimes of the flame. Therefore, different suitable extinction criteria are used. As a first crucial outcome, this work points out the suppressing effect shown by smaller droplets, which vaporize very early, as stressed out by Thomas [30]. Moreover, a parametric study stresses out the water barrier characteristics to express and quantify the parameters related to mitigation efficiency: a water barrier of $0.05 \%$ of liquid volume fraction is capable of mitigating deflagration flames, while a higher fraction is required to extinguish at detonation conditions. As already discussed by Ndubizu et al. [28], the relative importance of oxygen dilution is reported with respect to energy depleting and perturbation velocity of the flame. This latter 

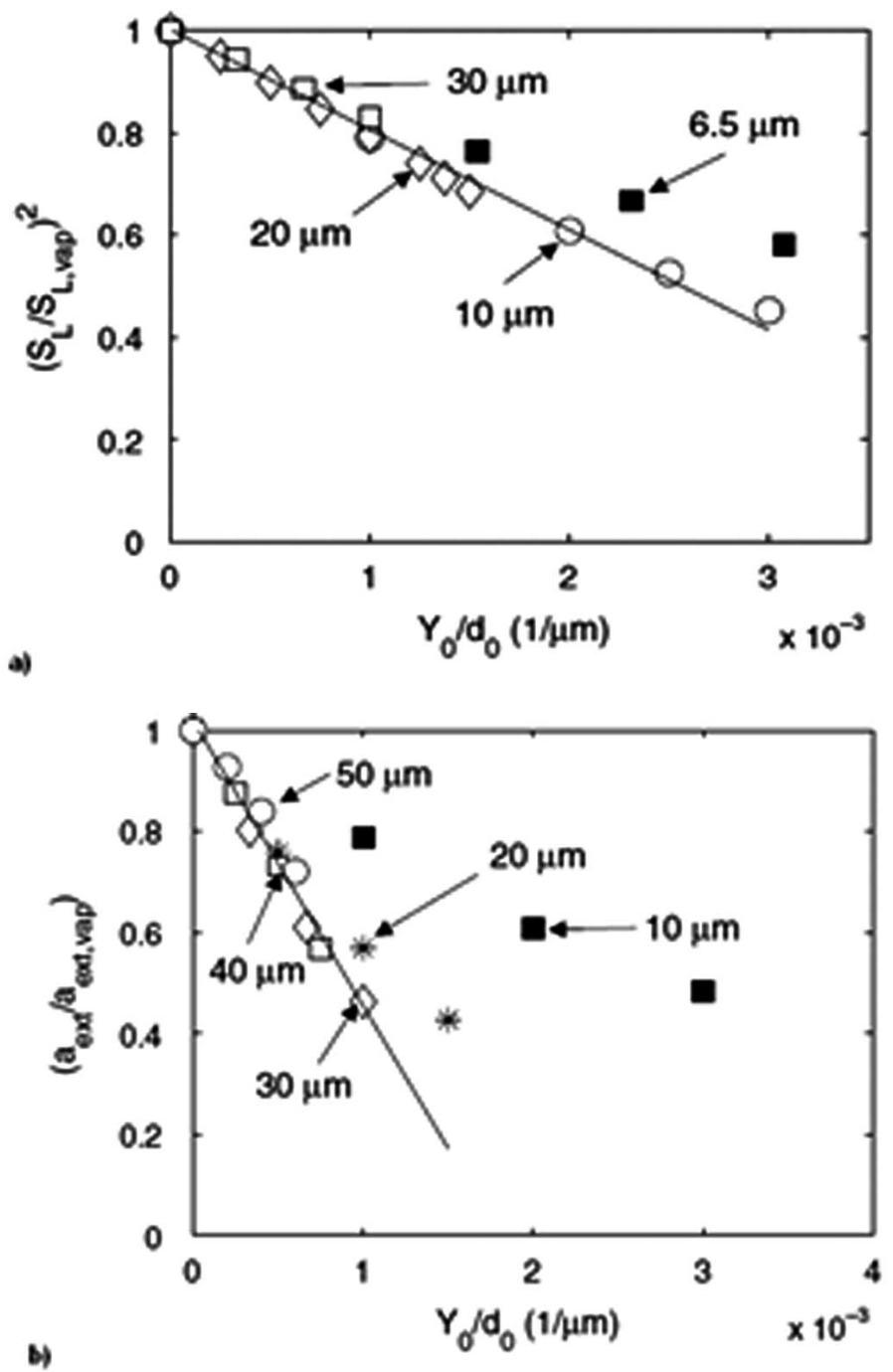

Fig. (9). Variation of the non-dimensional flame strength vs. droplet-surface area parameter for a) premixed and b) non-premixed flames [33].

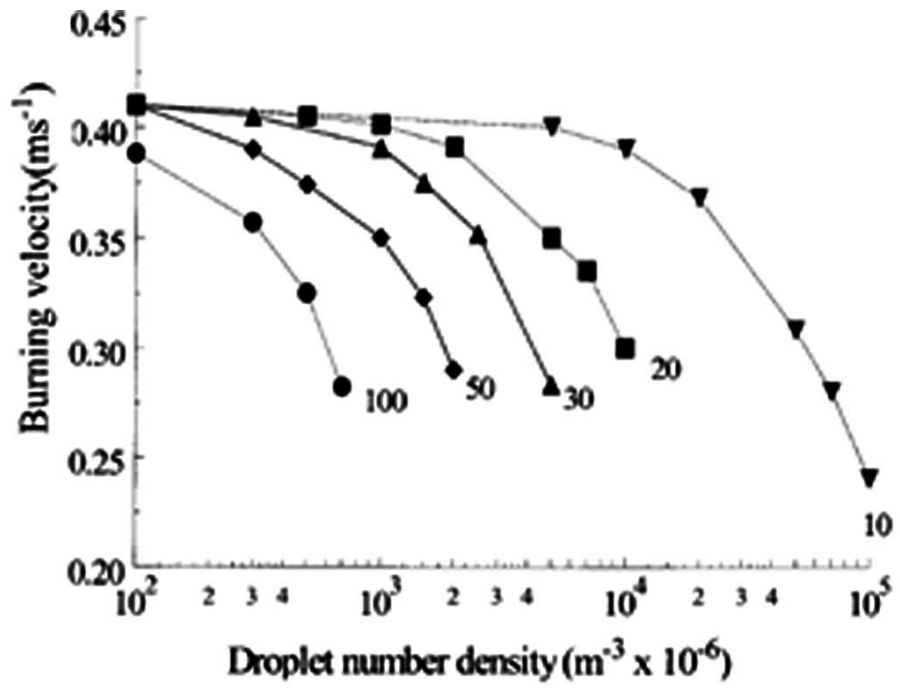

Fig. (10). Burning velocity of an atmospheric stoichiometric air-methane flame allowing for droplet evaporation as a function of droplet density. Different curves are presented as drop size varies in the range 10-100 $\mu \mathrm{m}$ [30].

parameter is strongly affected by oxygen dilution at deflagration regime, while the governing effect in detonation quenching is heat absorption by water droplets.
Some recent interest has been brought in about scaling models in fire protection, following the classic formulation of fire-suppression mechanism proposed by Heskestad [35] 
almost 30 years ago: it consists of a Froude-modeling referred to low drop Reynolds number. The same purpose has recently been pursued in a theoretical study on scaling of fire cooling by water mist performed by Jayaweera and $\mathrm{Yu}$ [36]. The authors have re-discussed Heskestad's model regarding high values of drop Reynolds number. The classic scaling relations are shown to be valid over a broad range of values, except for the drop size, that should be scaled with a 1/4power length instead of a 1/2-power. An experimental campaign has been performed to validate this extension of a preexisting theory with the appropriate modifications: the model has been validated by a comparison with experimental results over the range $3.3-824 \mathrm{~kW}$ of heat release rate. The proposed scaling model appears to be promising and of interest for system designers and researchers, who face fundamental phenomena related to mist cooling of fire gases.

\subsection{Zone Models}

An innovative numerical approach to predict water-mist performance is the well recognized one-zone model. It consists of assuming a total-flooding water-mist flow that fully mixes any enclosure, providing maximization of spatial dispersion and recirculation of fire gases independent of fire location. Therefore, any peculiar information on system design may be neglected, whereas other models need it as an input.

Some studies on the application of this approach to suppression within ventilated enclosures have been performed by Vaari $[37,38]$. The author states that a one-zone model is suitable to predict the transient behavior of water mist, as far as previous experimental observations tested the mist capability of mixing with the surrounding gas. A time-resolved method is applied to describe the transient behavior of temperature, gas density and composition, water-mist concentration. Evaporation process is conveniently modeled. Extinction is determined under the following hypothesis: inert gases and liquid water increase heat capacity of the gas providing a cooling effect on the flame. Moreover, direct cooling of the fuel surface is neglected; thereby, re-ignition potential is not taken into account. As a physical result, energy balance of the flame is expressed disregarding chemical effects and radiation losses: this represents a distinctive feature of the research. Validity of this numerical approach has been checked through a comparison with available experimental data (an example is reported in Fig. (11)): the test rooms had a volume ranging from 100 to $1000 \mathrm{~m}^{3}$; nominal heat release
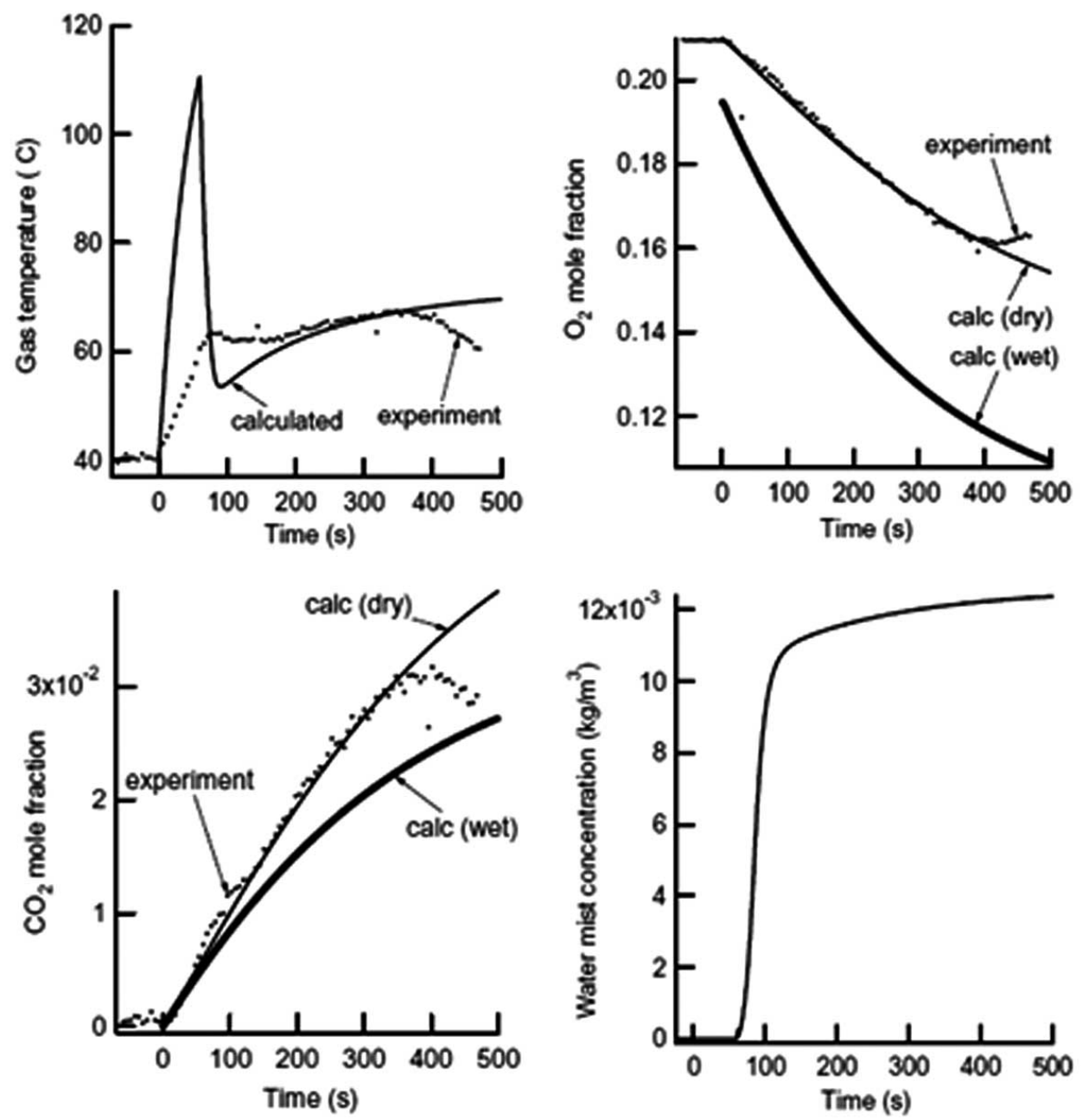

Fig. (11). Gas temperature, oxygen, carbon dioxide and water-mist concentration for a nominally 5.0 MW obstructed heptane spray fire in a nominally closed $3000 \mathrm{~m}^{3}$ machinery space (operative pressure: 70 bar, discharge flow rate: $5.1 \mathrm{~kg} \mathrm{~s}^{-1}$ ): comparison between numerical model and experimental data [38]. 
rate has been varied from 0.25 to $10 \mathrm{MW}$; water-flow rate has been varied over the range $1.1-8.52 \mathrm{~kg} \mathrm{~s}^{-1}$. The author states that it constitutes a reasonable engineering tool, but the one-zone approximation may lead to unrealistic results if flame interaction with enclosure boundaries are significant. Moreover, stratification due to buoyancy is not taken into account, as well as cooling effect of water droplets on the fuel surface: as a matter of fact, extinction mechanism is referred to the sole gas-phase effect.

One-zone-model approach has been critically reviewed by $\mathrm{Li}$ and Chow [39] as a numerical method for water-mist systems. The authors point out the suitability of this model to study fire extinction in obstructed zones, being it founded on droplet mixing with fire gas in a compartment. The important basis underlying this approach is that the room is considered a homogeneous region. Conservation equations for the two phases are reviewed as the theoretical background of the model and governing parameters are surveyed (discharge rate, drop size, fire size, ventilation, etc.). As already mentioned by Vaari [37,38], limitations of one-zone models are strongly connected to the numerous implemented approximations, which may cause misleading results about some specific fire scenarios: fire radiation, direct cooling effect, fuel properties and geometric characteristics of the scenario (especially obstructions) are neglected in this approach. However, Li and Chow point out the capability of one-zone models in evaluating the critical fire size for given ventilation conditions and water-mist characteristics (mainly referring to drop size). Therefore, this approach may be seen as a useful engineering tool, even if experiments are needed to properly determine the optimal system for a particular configuration.
An interesting enhancement to one-zone models has been proposed by Nyankina and Novozhilov [40]: the authors employ a two-phase zone model. In particular, the mist spray is simply represented as a heat sink, while a theoretical model is applied to the smoke layer in order to determine its thermal transient. Input data appear to be very simple: discharge characteristics of the nozzles and initial temperature conditions. The main result is sketched in Fig. (12), where curve 1 represents unbounded temperature, while curve 5 shows non-flashover conditions.

Flashover could be controlled if the discharge rate stands in the range between 0.075 and $0.1 \mathrm{~kg} \mathrm{~s}^{-1}$. This numerical outcome is of interest for design purposes, even if the employed computational domain is a simple room with one vent. Therefore, all the questions about applicability of zone models to real cases with obstructions and geometric singularities still appear to be discussed.

\subsection{Case Studies}

As far as water-mist technology has a strong technical interest, some studies have been carried out on certain physical cases or particular fire scenarios. These works are mainly computational, even if the more general and simple configurations have been investigated throughout experimental tests as well. An early review on water-mist applications has been proposed by Liu and Kim [41].

A practical work has been proposed by Back III et al. [42], bearing an industrial background. They have developed a quasi-steady-state model to predict effectiveness of water mist in extinguishing fuel-spray and pool fires. Their model has the specific purpose to discuss obstructed fires, where

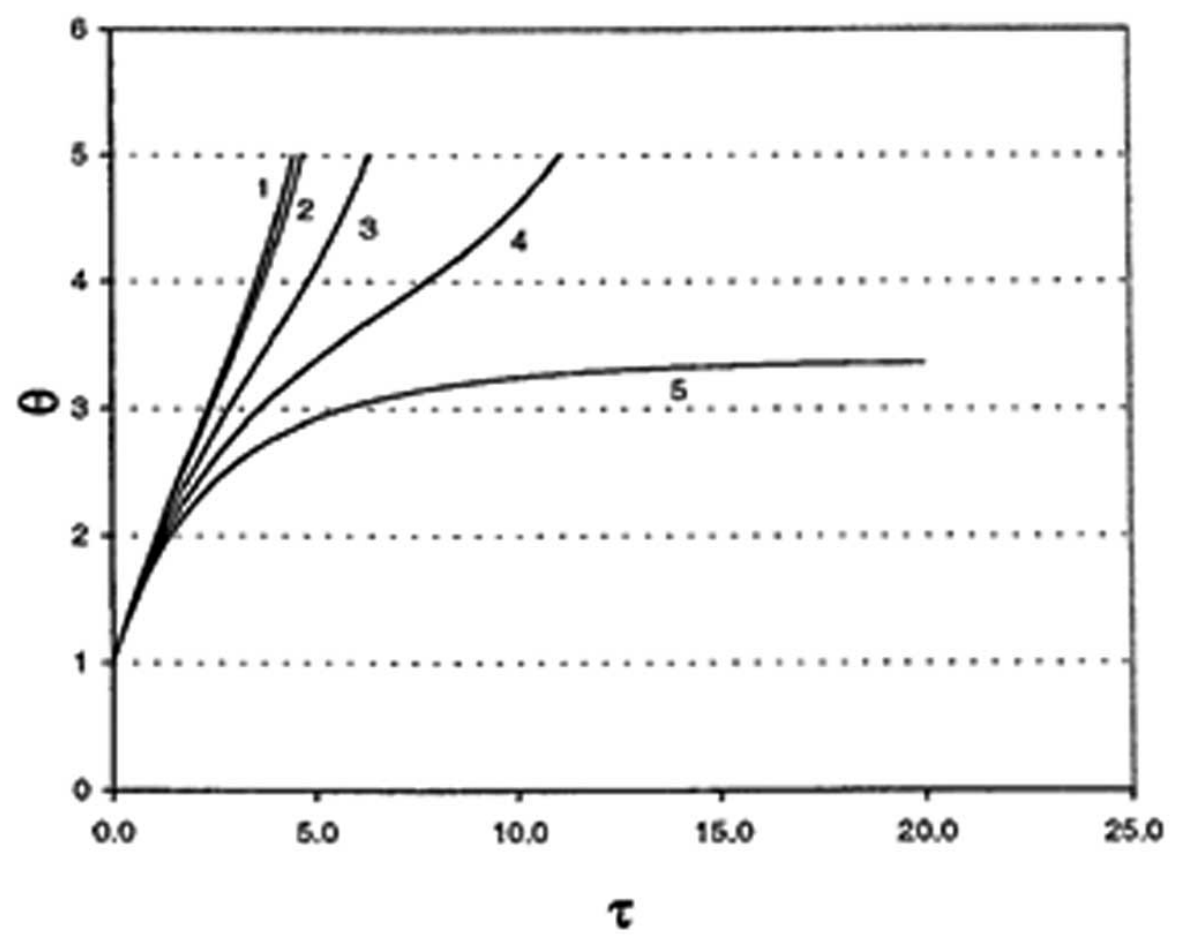

Fig. (12). Dimensionless temperature of the surrounding gases (reference temperature is the ambient one, $300 \mathrm{~K}$ ) versus dimensionless time (reference time is the characteristic heating time of the upper layer). Curves are related to different mist discharge rates: 1) $0.02,2$ ) $0.02,3$ ) $0.05,4) 0.075,5) 0.1 \mathrm{~kg} \mathrm{~s}^{-1}[40]$. 
suppression is mainly the result of oxygen dilution by water vapor. Therefore, mist-flame interactions are neglected and this constitutes a major difference from previously mentioned studies. Energy conservation is the key point that supports this model, while typical design parameters (case geometry, water flow rate, etc.) have to be a priori inserted. Steady-state temperature and oxygen concentration are predicted and yield the smallest fire the system can extinguish. A noteworthy experimental campaign features this study as an additional validating tool: the experiments have been conducted in shipboard machinery spaces, with compartment volumes ranging from 100 to $500 \mathrm{~m}^{3}$. Five systems and three ventilation conditions have been considered: a good agreement between experimental and numerical data is shown, even if some lack of accuracy occurs when fire size approaches the critical value (failed-extinction case). A similar study has been previously realized by Liu et al. [43] on extinguishment performance by continuous and cycling discharges of water mist in empty enclosures and machinery spaces. This work is purely experimental at full scale: heptane pool fires have been used with a heat release rate ranging from 50 to $520 \mathrm{~kW}$; the test room was $9.7 \mathrm{~m} \times 4.9 \mathrm{~m} \times$ $2.9 \mathrm{~m}$. A twin-fluid system has been challenged at relatively low pressure (slightly lower than 6 bar); the nozzle produced a flow rate of $51 \mathrm{~min}^{-1}$. Cycling discharge appears to be more effective in terms of both extinguishment and water consumption: the author stress out a higher depletion and dilution rate of oxygen together with a recurrent dynamic mixing due to the discharge cycles.

Kim and Ryou [44] have performed an experimental and numerical research on fire suppression in enclosures by water mist. Extinction time, temperature field and oxygen concentration have been measured in an enclosed compartment, that represents the test case for numerical simulations as well. Methanol and hexane fires have been employed as the test cases. The enclosed compartment had a size of $4.0 \mathrm{~m} \times$ $4.0 \mathrm{~m} \times 2.3 \mathrm{~m}$; K-type thermocouples have been employed to determine temperature profiles. The experimental campaign has produced an interesting quantitative result: the smokelayer temperature has shown to be affected by two different subsequent cooling effects in its temporal trend. The first one is sudden, while the second is gradual: the critical time is referred to the presence of sudden cooling. Numerical analyses have been carried out employing FDS and good agreement is reported between predicted and experimental results in terms of temperature and oxygen fraction. For instance, Fig. (13) shows the comparison between experimental and FDS results in terms of mean ceiling temperature for methanol fires.

A very specific study has been carried out by Shi et al. [45] on fires occurring in a large atrium. This work does not deal directly with water mist, but it constitutes a good reference for fire modeling with ad hoc built and commercial codes. The authors focus on spill-plume development and smoke filling: appropriate models have been proposed to discuss these two phenomena separately, while a zone-model has been finally developed to couple both of them. Smoke filling has been treated under a transport lag-time approach, that represents a quite innovative feature. FDS and CFAST have been employed as representative commercial codes of zone-models and CFD respectively. The obtained results have been compared to experimental data gained from a fullscale test series, where size of the atrium was $22.4 \mathrm{~m} \times 11.9$ $\mathrm{m} \times 27.0 \mathrm{~m}$ and maximum heat release rate of pool fires was about $700 \mathrm{~kW}$.

An interesting applied study has recently been performed by Chow et al. [46] on controlling plastic fires with water mist. This work particularly refers to PMMA and PVC: the latter has been proved to produce a larger quantity of smoke, even if its ignition appears to take more time. The suppression effect produced by a water-mist discharge has been investigated on burning PMMA and PVC in a cone calorimeter and this experimental approach represents a major contribution: a scaled nozzle has been developed to operate within a cone calorimeter allowing a small-scale test provided with a thorough record of temperature trend and heat release rate. Water mist appears to efficient in controlling plastic fires if the discharge time is sufficiently long; however, re-ignition may occur with an increase in smoke and $\mathrm{CO}$ generation, especially for PMMA. As a final remark, the authors state that operative pressure of the water-mist spray does not play a key role in this particular case: this observation is quite surprising, being operative pressure one of the governing
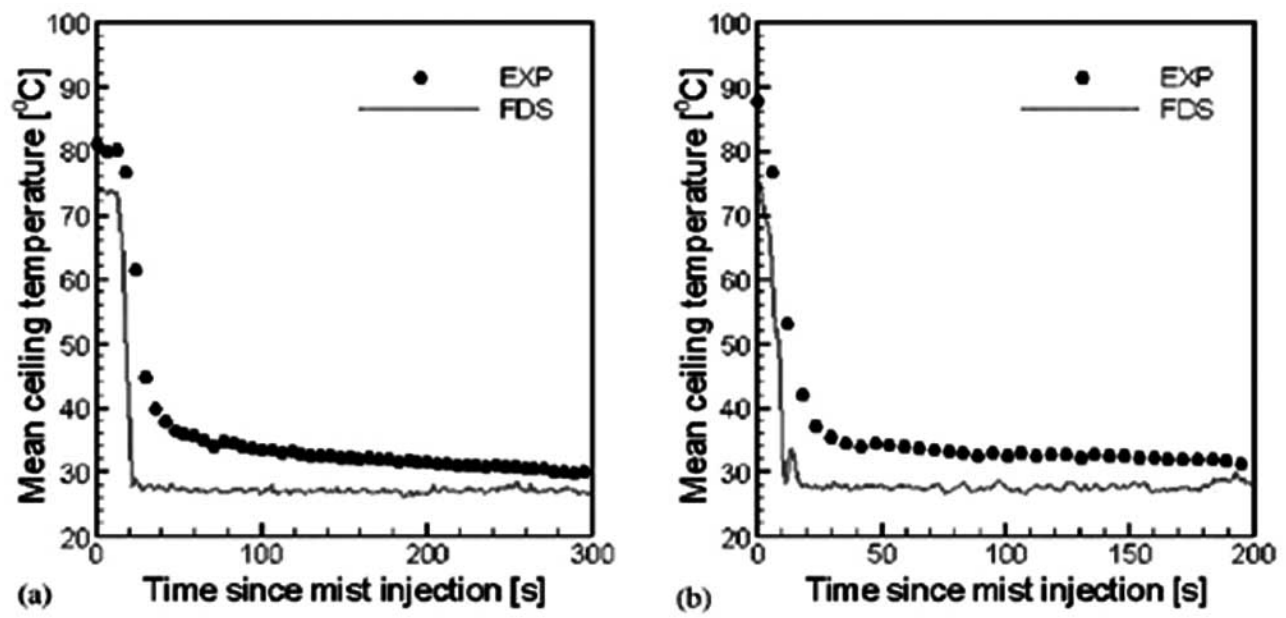

Fig. (13). Comparison between experimental and computational (FDS) results for methanol fires: injection time of water mist is a) $300 \mathrm{~s}$ and b) $70 \mathrm{~s}[44]$. 
parameters to determine drop size, together with injector geometry. However, full-scale tests are advised to enhance the comprehension on the effective capability of water mist in controlling this fire typology.

\subsection{Additional Studies}

Finally, it is also worthwhile to overview other research activities in water-mist field, which may not be directly connected to the main aspects covered by the present work, but represent key points to enhance system capabilities. First of all, a brief note is required about additives, which now constitute are a major challenge: they are sought to improve fireextinguishing efficiency with a contemporary reduction of metal corrosion and toxicity. They are still subject of research rather than commonly employed in industry, because questions about concentration, chemical characteristics and response to interaction with fire still need to be thoroughly answered. As an example, Xiaomeng et al. [47] have studied and proposed new MC (Multi Composition) additives consisting of carbamide, dymethilformamide and sodiumcarboxide. Another work has recently been published on the evaluation of water-mist performance under the introduction of a commercial surfactant (LeFort et al. [48]). In particular, the foaming effect of fluorinated additives is stressed out as an enhancement of suppression efficiency together with preventing re-ignition of class $B$ fires.

Other works have been aimed at analyzing heat-transfer phenomena between water mist and solid surfaces: water mist can also be employed as a cooling technology and a deep comprehension of the involved physics is required. This field also represents a crucial point for industrial applications, as far as many cooling technologies nowadays employ very fine droplets. Heat transfer plays the key role, but also impact processes need to be fundamentally investigated, as shown in Sozbir et al. [49]. The authors have experimentally investigated heat transfer between a water-mist-fed air jet and metal surfaces at high temperature (greater than 500 ${ }^{\circ} \mathrm{C}$ ). The main proposed outcome consists of reporting the trend of heat-transfer coefficient with respect to liquid mass flux at different jet velocities (Fig. (14)).
Heat-transfer coefficient dramatically increases as small amounts of water are added to the air jet. Moreover, it also grows as velocity becomes higher. It is noteworthy to point out that air and mist heat transfer are independent: the latter obviously increases as water flux grows, while it is almost independent of velocity. This latter statement is quite interesting and suggests an opposite trend to flow-flame interaction, which is enhanced by water-mist pressure, that brings higher velocities.

Some mention should be given to the studies on extinguishment of hot cooking-oil fires by water-mist systems. These works have been conducted by Liu et al. [50,51] from an almost experimental point of view. The authors stress out the high effectiveness of water mist in extinguishing and preventing re-ignition: as a matter of fact, mist cools down from ignition point (almost $360{ }^{\circ} \mathrm{C}$ ) up to a temperature lower than flash point $\left(200^{\circ} \mathrm{C}\right)$. Moreover, experiments have shown that boil-over or spillage is not present when water mist is discharged into the oil at high temperature (greater than $300{ }^{\circ} \mathrm{C}$ ), while it is observed if oil temperature is relatively low (almost $200{ }^{\circ} \mathrm{C}$ ). The same authors have also carried out an experimental and theoretical research on portable water-mist systems with respect to a variety of fire scenarios [52]. Among these latter, flammable liquids, cooking oil and wood cribs stand as the most interesting applications. Different portable extinguishers have been developed to the purpose and generally good effectiveness has been achieved in suppression and extinguishment, provided that suitable water-flux density and spray momentum are imposed.

A recent interest in water-mist systems has been shown for fire protection in tunnels. This application represents a real challenge for water mist because of the very large scale of the possible scenarios and the extremely high cost of fire events in tunnels in terms of harms and damages. It is worthwhile to mention the SOLIT (Safety Of Life In Tunnels) and the UPTUN (UPgrading methods for fire safety in existing TUNnels) as two of the largest research projects on the subject: both academic and industrial partners are involved and this latter is supported by the European Community. A recent numerical work by Nmira et al. [53] has been

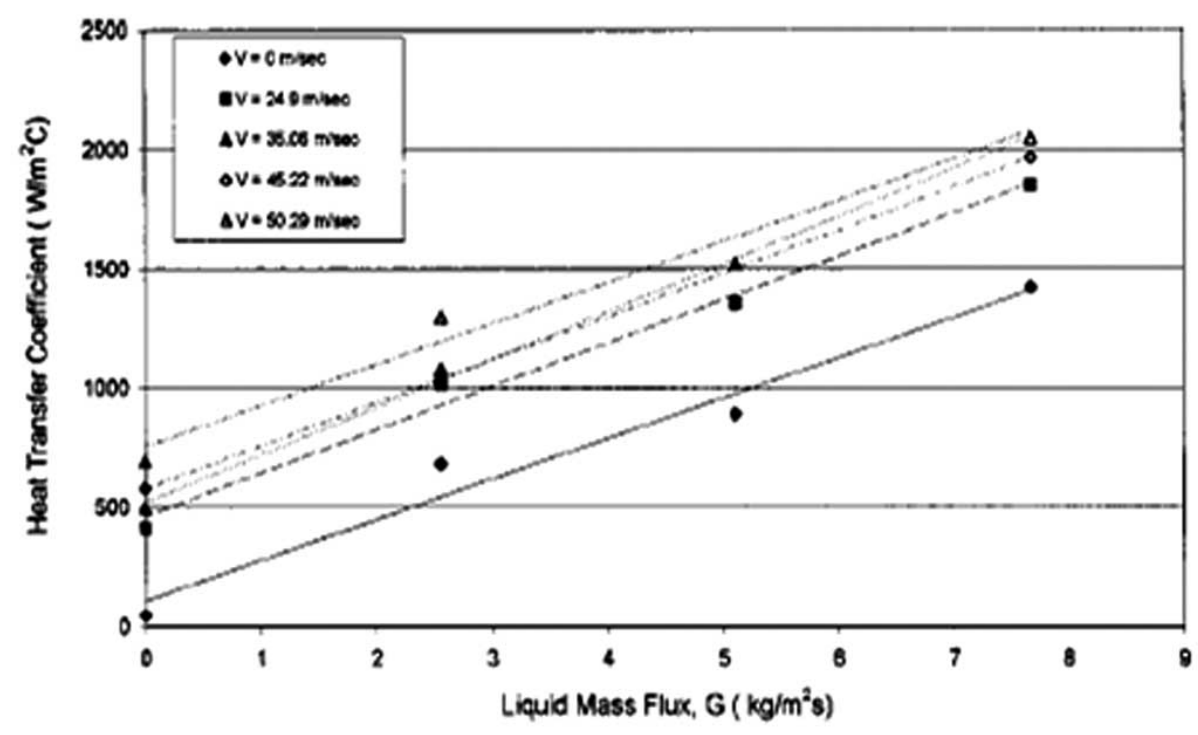

Fig. (14). Heat-transfer coefficient vs. liquid mass flux at different jet velocities [49]. 
published in the open literature. It mainly refers to thermoplastic fires occurring in a full-scale ventilated tunnel. A Eulerian-Eulerian model is employed to describe both the gas and the liquid phase; the simulations show that fire extinction is performed during the transient flow-flame interaction, which is followed by a quasi-steady state. This outcome appears to be connected to a rapid decrease of pyrolysis rate in the fuel package. However, extinction is successfully achieved only at high water-flow rates; otherwise, quasisteady conditions are quickly reached and an increase in flow rate becomes almost ineffective in mitigation. As a suggestion to this specific application, experimental data would be highly recommended to serve as a quantitative tool to validate numerical results.

\section{SUMMARY AND CONCLUSIONS}

An attempt of comprehensive review of water-mist systems has been presented. Theoretical results, experimental studies and modeling approaches have been reported, and much fundamental information from early studies as well as important contributions from recent research approaches have been pointed out.

The water mist fire suppression systems are increasingly popular since they are an excellent alternative to halon fire protection systems. They are now being used in many areas, including marine and industrial applications. However, even if the water mist application is a sufficiently mature technology, many problems concerning its behavior, characterization and numerical simulation are still unsolved or roughly approximated. Moreover, fire test protocols and specific water mist standards are not worldwide available.

Regardless of the recognized characteristics of watermist systems and in spite of the important literature studies on the parameters that govern water-mist behavior, some considerations seem to hold:

a) Water-mist phenomenological characteristics are very complex and not completely understood;

b) Due to its effectiveness in achieving relevant results in terms of fire control and suppression, water-mist systems are too important to be approached by limited correlations and/or approximations;

c) Water-mist mechanisms have to be conclusively identified from the experimental data. Nonetheless, slow but progressive developments have been observed, and more promising considerations can be made for future work:

d) New experimental techniques have been developed, and more refined capabilities are needed in terms of measurements of drop size and momentum.

e) Recent improvements of visualization techniques have provided excellent results in the analysis of droplet behavior, and very high-speed videos are needed to obtain more time-resolved images of droplets.

f) Modeling capabilities appear to be strongly dependent on the experimental information, but nowadays the improved computational resources allow researchers to approach the difficult task of numerical simulation of water-mist behavior within and without fire envi- ronment. In particular, however, much stronger efforts should be aimed at developing codes and routines which are solely dedicated to water-mist simulations rather than being adapted from other, albeit effective, tools for sprinklers or different fire-protection systems.

In few words, up to date the water-mist systems seem to be very promising in terms of efficiency, application potential and industrial standardization, but a lot of experimental and numerical research, as well as much application experience, are still needed to gain better knowledge about the capabilities of those systems in fire control and suppression.

\section{ACKNOWLEDGMENTS}

The authors gratefully acknowledge Prof. André W. Marshall and Prof. Marino di Marzo for their assistance. A special acknowledgment also goes to Mr. Massimo Bettati (Bettati Antincendio S.r.l., Reggio Emilia, Italy) for his technical and financial support during the entire period of research collaboration between University of Maryland, USA, and Università degli Studi di Modena e Reggio Emilia, Italy. The financial contributions of the Italian MIUR, the Regione Emilia-Romagna (Italy) and the Fondazione Cassa di Risparmio di Modena (Italy) are highly appreciated.

\section{NOMENCLATURE}

$C_{D}$

$=$ Area $\left[\mathrm{m}^{2}\right]$, empirical constant (see eq. (6))

$c_{p}$

$c_{p}$

$=$ Drag coefficient

$=$ Specific heat at constant pressure $\left[\mathrm{J} \mathrm{kg}^{-1} \mathrm{~K}^{-1}\right]$

$d \quad=$ Diameter $[\mathrm{m}]$

$D \quad=$ Mass diffusivity $\left[\mathrm{m}^{2} \mathrm{~s}^{-1}\right]$

$E \quad=$ Activation energy $\left[\mathrm{J} \mathrm{kg}^{-1}\right]$

$E_{T} \quad=$ Total emissive power of a black body [ $\left.\mathrm{W} \mathrm{m}^{-2}\right]$

$E_{\lambda T}=$ Spectral emissive power of a black body $\left[\mathrm{W} \mathrm{m}{ }^{-2}\right.$ $\mu \mathrm{m}^{-1}$ ]

$=$ Angular dissymmetry factor

$=$ Gravity acceleration $\left(=9.807 \mathrm{~m} \mathrm{~s}^{-2}\right)$

$=$ Convective heat-transfer coefficient $\left[\mathrm{W} \mathrm{m} \mathrm{m}^{-2} \mathrm{~K}^{-1}\right]$

$h_{m} \quad=$ Mass transfer coefficient $\left[\mathrm{m} \mathrm{s}^{-1}\right]$

$k=$ Thermal conductivity $\left[\mathrm{W} \mathrm{m}^{-1} \mathrm{~K}^{-1}\right]$

$k_{\text {ext }}=$ Extinction coefficient (see eq. (9))

$L=$ Thickness [m]

$M \quad=\operatorname{Load}[\mathrm{kg}]$

$m \quad=$ Mass $[\mathrm{kg}]$

$p \quad=$ Pressure $[\mathrm{Pa}]$

$q_{e} \quad=$ Latent heat $\left[\mathrm{J} \mathrm{kg}^{-1}\right]$

$Q_{\text {ext }}=$ Extinction efficiency

$q_{t r}=$ Total transmitted power $\left[\mathrm{W} \mathrm{m}^{-2}\right]$

$q_{\lambda}=$ Transmitted spectral flux $\left[\mathrm{W} \mathrm{m}^{-2} \mu \mathrm{m}^{-1}\right]$

$R=$ Combustion rate $\left[\mathrm{kg} \mathrm{s}^{-1}\right]$

$R=$ Ideal gas constant $\left(=8.314 \mathrm{~J} \mathrm{~mol}^{-1} \mathrm{~K}^{-1}\right)$ 


$\begin{array}{ll}r & =\text { Transmitted fraction of the total heat flux } \\ R_{t} & =\text { Reflection factor } \\ T & =\text { Temperature }[\mathrm{K}] \\ t & =\text { Time }[\mathrm{s}] \\ V & =\text { Velocity }\left[\mathrm{m} \mathrm{s}^{-1}\right] \\ w & =\text { Albedo } \\ x & =\text { Molecular fraction }\end{array}$

\section{Greek symbols}

$\begin{array}{lll}\alpha & =\text { Empirical constant (see eq. (6)) } \\ \beta & =\text { Empirical constant (see eq. (6)) } \\ \gamma & =\text { Coefficient expressed by eq. (8) } \\ \lambda & =\text { Wavelength }[\mathrm{m}] \\ v & =\text { Kinematic viscosity }\left[\mathrm{m}^{2} \mathrm{~s}^{-1}\right] \\ \rho & =\text { Density }\left[\mathrm{kg} \mathrm{m}^{-3}\right] \\ \tau & = & \text { Effective extinction coefficient (see eq. (10)) } \\ & {\left[\mathrm{m}^{2}\right]}\end{array}$

\section{Subscripts}

$\begin{array}{ll}d & =\text { Droplet } \\ f & =\text { Fuel } \\ g & =\text { Gas } \\ o x & =\text { Oxygen } \\ s & =\text { Saturation condition } \\ v & =\text { Vapor }\end{array}$

\section{REFERENCES}

[1] NFPA 750: Standards on water mist fire protection systems, National Fire Protection Association, 2006.

[2] FM5560: Approval Standard for Water Mist Systems, Class no. 5560, FM Approvals LLC., 2005.

[3] A.E. Cote, J.L. Linville, (Eds.), Fire Protection Handbook. Quincy, MA, USA: National Fire Protection Association, 1997.

[4] D.J. Rasbash, Z.W. Rogowski, "Extinction of fires in liquids by cooling with water sprays", Combust. Flame, vol. 1, pp. 453-466, 1957.

[5] D.J. Rasbash, Z.W. Rogowski, G.W.V. Stark, "Mechanisms of extinction of liquid fires with water sprays", Combust. Flame, vol. 4, pp. $223-234,1960$

[6] G. Grant, J. Brenton, D. Drysdale, "Fire suppression by water sprays", Prog. Energy Combust. Sci., vol. 26, pp. 79-130, 2000.

[7] K.A. Notarianni, "Water mist fire suppression systems", in Technical Symposium on Halon Alternatives, 1994, pp. 57-64.

[8] J.R. Mawhinney, J.K. Richardson, "A Review of Water Mist Fire Suppression Research and Development, 1996", Fire Technol., vol. 33, pp. 54-90, 1997.

[9] Z. Liu, A.K. Kim, "A Review of Water Mist Fire Suppression Systems - Fundamental Studies", J. Fire Prot. Eng., vol. 10, pp. 32-50, 1999.

[10] B. Yao, W.K. Chow, "A review of water mist fire suppression systems", J. Appl. Fire Sci., vol. 10, pp. 277-294, 2000-2001.

[11] A. Jones, P.F. Nolan, "Discussions on the use of fine water sprays or mists for fire suppression”, J. Loss Prev. Process Ind., vol. 8, pp. 17-22, 1995.

[12] D.J. Rasbash, "Heat transfer between water sprays and flames of freely burning fires", in symposium on the interaction of fluids and Particles, 1962, pp. 217-223.

[13] W.K. Chow, and B. Yao, "Numerical modeling for interaction of a water spray with smoke layer", Numer. Heat Transf. A - Appl., vol. 39, pp. 267-283, 2001.
[14] G.G. Back III, C.L. Beyler, R. Hansen, "The Capabilities and Limitations of Total Flooding, Water Mist Fire Suppression Systems in Machinery Space Applications", Fire Technol., vol. 36, pp. 8-23, 2000.

[15] T. Log, "Radiant Heat Attenuation in Fine Water Sprays", in $7^{\text {th }}$ International Fire Science and Engineering Conference, 1996, pp. 425-434.

[16] A. Coppalle, D. Nedelka, B. Bauer, "Fire protection: Water curtains", Fire Saf. J., vol. 20, pp. 241-255, 1993.

[17] J. Suh, A. Atreya, "Effect of Water Vapor on Radiative Counterflow Diffusion Flames", in ASME International Mechanical Engineering Congress and Exposition, 1995, part 2, pp. 53-58.

[18] B. Yao, W. Fan, G. Liao, "Interaction of water mists with a diffusion flame in a confined space", Fire Saf. J., vol. 33, pp. 129-139, 1999.

[19] C. Crowe, M. Sommerfeld, Y. Tsuji, Multiphase Flows with Droplets and Particles. Boca Raton, FL, USA: CRC Press, 1998.

[20] J.R. Mawhinney, G.V. Hadjisophocleous, "The Role of Fire Dynamics in Design of Water Mist Fire Suppression Systems", in $7^{\text {th }}$ International Fire Science and Engineering Conference, 1996, pp. 415-424.

[21] W.K. Chow, B. Yao, "Discussion on the Potential Application of Water Mist System for Fire Protection in Atria", ASHRAE Trans., vol. 107: Part 1, pp. 171-177, 2001.

[22] B. Paulsen Husted, "Experimental measurements of water mist systems and implications for modelling in CFD", Doctoral Thesis, Lund University, Sweden, 2007.

[23] B. Paulsen Husted, P. Petersson, I. Lund, G. Holmstedt, "Comparison of PIV and PDA droplet velocity measurement techniques on two high-pressure water mist nozzles", Fire Saf. J., vol. 44, pp. 1030-1045, 2009.

[24] P.E. Santangelo, N. Ren, P. Tartarini, and A.W. Marshall, "Spray characterization of high pressure water mist injectors: experimental and theoretical analysis", in $22^{\text {nd }}$ European Conference on Liquid Atomization and Spray Systems - ILASS 2008, 2008, paper ILASS08-10-5.

[25] P.E. Santangelo, P. Tartarini, B. Pulvirenti, and P. Valdiserri, "Discharge and Dispersion in Water-Mist sprays: Experimental and Numerical Analysis", in $11^{\text {th }}$ triennial international conference on liquid atomization and spray systems - ICLASS 2009, 2009, paper ICLASS09-051.

[26] P.E. Santangelo, "Characterization of water-mist sprays: experimental and theoretical analysis of atomization and dispersion", Doctoral thesis, Università degli Studi di Modena e Reggio Emilia, Italy, 2009.

[27] J. Trelles, J.R. Mawhinney, P.J. DiNenno, "Characterization of a High-Pressure Multi-jet Water Mist Nozzle for the Purpose of Computational Fluid Dynamics Modeling”, in Jornada Tecnica Internacional "Los modelos de Simulacion Computacional en la Ingenieria y la Investigacion de Incendios", 2004, pp. 261-270.

[28] C.C. Ndubizu, R. Ananth, P.A. Tatem, and V. Motevalli, "On water mist fire suppression mechanisms in a gaseous diffusion flame", Fire Saf. J., vol. 31, pp. 253-276, 1998.

[29] B.T. Fisher, A.R. Awtry, R.S. Sheinson, J.W. Fleming, "Flow behavior impact on the suppression effectiveness of sub-10- $\mu \mathrm{m}$ water drops in propane/air co-flow non-premixed flames", Proc. Combust. Inst., vol. 31, pp. 2731-2739, 2007.

[30] G.O. Thomas, "The Quenching of Laminar Methane-Air Flames by Water Mists", Combust. Flame, vol. 130, pp. 147-160, 2002.

[31] K.C. Adiga, R.F. Hatcher Jr., R.S. Sheinson, F.W. Williams, S. Ayers, "A computational and experimental study of ultra fine water mist as a total flooding agent", Fire Saf. J., vol. 42, pp. 150-160, 2007.

[32] A.M. Lentati, H.K. Chelliah, "Dynamics of Water Droplets in a Counterflow Field and their Effect on Flame Extinction", Combust. Flame, vol. 115, pp. 158-179, 1998.

[33] H.K. Chelliah, "Flame inhibition/suppression by water mist: Droplet size/surface area, flame structure, and flow residence time effects", Proc. Combust. Inst., vol. 31, pp. 2711-2719, 2007.

[34] T. Parra, F. Castro, C. Méndez, J.M. Villafruela, M.A. Rodrìguez, "Extinction of premixed methane-air flames by water mist", Fire Saf. J., vol. 39, pp. 581-600, 2004.

[35] G. Heskestad, "Physical modeling of fire", J. Fire Flammability, vol. 6 , pp. 254-273, 1975. 
[36] T.M. Jayaweera, H.-Z. Yu, "Scaling of fire cooling by water mist under low drop Reynolds number conditions", Fire Saf. J., vol. 43, pp. 63-70, 2008

[37] J. Vaari, "A Study of Total Flooding Water Mist Fire Suppression System Performance Using a Transient One-Zone Computer Model", Fire Technol., vol. 37, pp. 327-342, 2001.

[38] J. Vaari, "A transient one-zone computer model for total flooding water mist fire suppression in ventilated enclosures", Fire Saf. J., vol. 37, pp. 229-257, 2002.

[39] Y.F. Li, W.K. Chow, "Modelling of water mist fire suppression systems by a one-zone model", Combust. Theory Model., vol. 8, pp. 567-592, 2004.

[40] N. Nyankina, V. Novozhilov, "Prediction of fire environment under water mist suppression conditions by two-phase zone model", $J$. Appl. Fire Sci., vol. 10, pp. 193-214, 2000-2001.

[41] Z. Liu, A.K. Kim, "A Review of Water Mist Fire Suppression Technology: Part II - Application Studies", J. Fire Prot. Eng., vol. 11, pp. 16-42, 2001

[42] G.G. Back III, C.L. Beyler, R. Hansen, “A quasi-steady-state model for predicting fire suppression in spaces protected by water mist systems", Fire Saf. J., vol. 35, pp. 327-362, 2000.

[43] Z. Liu, A.K. Kim, J.Z. Su, "Examination of the extinguishment performance of a water mist system using continuous and cycling discharges", Fire Technol., vol. 35, pp. 336-361, 1999.

[44] S.C. Kim, H.S. Ryou, "An experimental and numerical study on fire suppression using a water mist in an enclosure", Build. Environ., vol. 38, pp. 1309-1316, 2003.
[45] C.L. Shi, W.Z. Lu, W.K. Chow, R. Huo, "An investigation on spill plume development and natural filling in large full-scale atrium under retail shop fire", Int. J. Heat Mass Transf., vol. 50, pp. 513$529,2007$.

[46] W.K. Chow, J. Qin, S.S. Han, "Bench Scale Tests on Controlling Plastic Fires with Water Mists", Chem. Eng. Technol., vol. 28, pp. 1041-1047, 2005.

[47] Z. Xiaomeng, L. Guangxuan, and C. Bo, "Improvement of water mist's fire-extinguishing efficiency with MC additive", Fire Saf. J., vol. 41, pp. 39-45, 2006

[48] G. LeFort, A.W. Marshall, M. Pabon, "Evaluation of Surfactant Enhanced Water Mist Performance", Fire Technol., vol. 45, pp. 341-354, 2009.

[49] N. Sozbir, Y.W. Chang, S.C. Yao, "Heat Transfer of Impacting Water Mist on High Temperature Metal Surfaces", J. Heat Transf. - Trans. ASME, vol. 125, pp. 70-74, 2003.

[50] Z. Liu, A.K. Kim, D. Carpenter, J.M. Kanabus-Kaminska, "extinguishment of cooking oil fires by water mist fire suppression systems", Fire Technol., vol. 40, pp. 309-333, 2004.

[51] Z. Liu, D. Carpenter, A.K. Kim, "Cooling characteristics of hot oil pool by water mist during fire suppression", Fire Saf. J., vol. 43, pp. 269-281, 2008.

[52] Z. Liu, A.K. Kim, and D. Carpenter, "A study of portable water mist fire extinguishers used for extinguishment of multiple fire types", Fire Saf. J., vol. 42, pp. 25-42, 2007.

[53] F. Nmira, J.L. Consalvi, A. Kaiss, A.C. Fernandez-Pello, B. Porterie, "A numerical study of water mist mitigation of tunnel fires", Fire Saf. J., vol. 44, pp. 198-211, 2009. 